\title{
DINÂMICAS DE INTEGRAÇÃO AÉREA E ESTRATÉGIAS DE USO CORPORATIVO DO TERRITÓRIO BRASILEIRO: O CASO DA AZUL LINHAS AÉREAS.
}

\author{
Ivy Mori Moreira ${ }^{1}$ \\ Francisco das Chagas do Nascimento $\mathrm{Jr}^{2}$
}

Resumo: Nas últimas décadas, o sistema de transporte aéreo brasileiro experimentou um significativo processo de expansão e reconfiguração, resultado, por um lado, da ampliação das demandas por circulação rápida instituída no território nacional e impulsionado, por outro lado, pelas políticas neoliberais de "desregulação do setor aéreo" promovidas pelo Estado. A pesquisa que resultou neste artigo teve como objetivo geral compreender a lógica que rege o atual processo de integração aérea do território nacional e buscou analisar, especialmente, as estratégias de uso do território estabelecidas pelas empresas aéreas operantes no país. Para tanto, realizou-se uma breve análise da territorialidade da Azul Linhas Aéreas. O estudo da topologia territorial da Azul se constituiu num caso bastante representativo para a compreensão do atual processo de integração aérea nacional, bem como se definiu como um exemplo emblemático do uso seletivo, desigual e hierárquico do território realizado pelas grandes companhias aéreas no Brasil.

Palavras - chave: Integração territorial; Sistema de transporte aéreo; Fluidez espacial; Uso corporativo do território; Azul Linhas Aéreas.

\section{DYNAMICS OF AEREA INTEGRATION AND STRATEGIES OF CORPORATE USE OF THE BRAZILIAN TERRITORY: THE CASE OF AZUL LINHAS AÉREAS.}

\begin{abstract}
In Brazil, the air transport system has played an important role in the process of national integration. However, over the last few decades, a new dynamics of organization and operation of the national air network has been established, resulting, on the one hand, from the expansion of the demands for rapid circulation in the country and, on the other, a consequence of the neoliberal policies of " deregulation of the air sector "promoted by the Brazilian State. In this sense, the present research proposal has as general objective to understand the logic that governs the current process of aerial integration of the national territory and to analyze, specially, the strategies of use of the territory established by the airlines operating in the country. Therefore, we propose a brief analysis of the territoriality of Azul Linhas Aéreas. The study of the territorial topology of Azul is a very relevant case for understanding the new phase of national air integration, as well as being an emblematic example of the current selective, unequal and hierarchical use of the Brazilian territory practiced by airlines.
\end{abstract}

Keywords: Territorial integration; air transport system; corporate use of the territory; Azul Linhas Aéreas.

\footnotetext{
${ }^{1}$ Universidade Federal Rural do Rio de Janeiro. Graduada em Geografia. ivymoriufrrj@gmail.com.

2 Universidade Federal Rural do Rio de Janeiro. Departamento de Geografia - Instituto Multidisciplinar. fcnascimentojr@gmail.com.
} 


\section{INTRODUÇÃO}

No Brasil - país de dimensões continentais - o sistema de transporte aéreo tem cumprido, historicamente, importante papel no processo de integração nacional. Ao possibilitar a superação rápida de longas distâncias, a aviação permitiu ao Estado assegurar o controle sobre áreas parcamente ocupadas do território, bem como viabilizou a inserção de parcelas do território à lógica do mercado nacional (GALLO, 2006).

Todavia, ao longo das últimas décadas, um expressivo processo de expansão do sistema de transporte aéreo regular ${ }^{3}$ ocorreu no país. Não apenas o número de voos e de passageiros transportados foi consideravelmente ampliado, como um conjunto de lugares passou a ser alcançado, com maior regularidade, por voos domésticos, demonstrando, de certo modo, uma intensificação do processo de articulação aérea do território brasileiro.

Consequência, por um lado, das novas demandas por circulação rápida estabelecidas pela moderna organização produtiva do território e, por outro lado, favorecido pela política neoliberal de "desregulação do setor aéreo" promovida pelo Estado brasileiro a partir dos anos 1990, expandiu-se o sistema de transporte aéreo regular, ainda que desigualdades regionais quanto a densidade dos fluxos aéreos (quantidade e frequência de voos) tenham persistido.

Assim, foi diante deste contexto de expansão dos fluxos aéreos nacionais e de instalação de um novo sistema de regulação política do território - responsável por ampliar o poder de controle das empresas sobre o mercado de aviação doméstica que a presente proposta de pesquisa teve como objetivo geral analisar a atual dinâmica de integração aérea do território brasileiro. Em especial, o propósito foi o de compreender como as empresas aéreas operantes no Brasil vêm estabelecendo uma maior articulação (aérea) entre os lugares e regiões do país, oportunizando, desse modo, uma maior fluidez na circulação de passageiros no espaço nacional. Outro objetivo do trabalho foi o de reconhecer as estratégias corporativas de uso do território implantadas pelas companhias aéreas, e avaliar suas consequências para a consecução da efetiva integração nacional.

Para tanto, o trabalho foi organizado em três partes, além da introdução e das considerações finais. Em um primeiro instante buscou-se reconhecer os fatores que condicionaram o recente processo de expansão dos fluxos aéreos no Brasil, e, concomitantemente, apresentou-se a atual configuração da rede aérea nacional, um produto, a um só tempo, dos dinamismos produtivos do território e da implantação de novas formas políticas de regulação territorial que redefiniram as possibilidades de ação das empresas aéreas no país.

$\mathrm{Na}$ segunda parte do trabalho, compreendendo território e mercado como sinônimos ${ }^{4}$ (SANTOS, 1994), e reconhecendo um processo de oligopolização do

\footnotetext{
${ }^{3}$ De acordo com Gallo (2005), o sistema de trasporte aéreo pode ser dividido em duas categorias. O sistema de transporte aéreo rígido, caracterizado por possuir linhas aéreas com horários de vôos fixos e ligações pré-estabelecidas entre as cidades; e o sistema de transporte aéreo flexível, cujas principais marcas são a existência de linhas aéreas não regulares e o estabelecimento de ligações aéreas segundo demandas particulares (como taxi aéreos, entre outros). Vale esclarecer que em nosso trabalho abordaremos, especialmente, a expansão, a organização e o funcionamento do sistema de transporte aéreo rígido, constituído tanto pelo sistema de transporte aéreo rígido nacional, quanto pelo sistema de transporte aéreo rígido regional.

${ }^{4}$ É importante esclarecer que para Santos et al. (2000), o território deve ser visto como expressão do espaço banal, isto é, como o espaço de todos os agentes sociais. Para este autor, o território se constitui num quadro de vida onde coexistem diferentes agentes sociais - em que pese seu poder e força desiguais - cada qual com seus próprios interesses e projetos de uso do território. Segundo Santos (1994, p. 89), território e mercado são sinônimos na medida em que "(...) é neste espaço que um mercado hierarquizado e articulado pelas firmas hegemônicas, nacionais e estrangeiras comandam o território com apoio do Estado”.
} 
mercado brasileiro de voos domésticos, o intuito foi o de demonstrar como, atualmente, se realiza um uso seletivo, desigual e hierárquico do território pelas empresas aéreas, assim como se buscou identificar a territorialidade diferencial das companhias mais proeminentes do país.

Por fim, como uma forma de avaliar um caso concreto e emblemático da dinâmica recente de integração aérea do território, propôs-se uma análise da territorialidade da Azul Linhas Aéreas. Esta empresa passou a desempenhar relevante papel no processo de reconfiguração da malha aérea nacional, fortalecendo novos padrões de interações espaciais entre centros urbanos de diferentes níveis no país. Ademais, a partir da análise de sua topologia territorial, isto é, através do reconhecimento do conjunto de pontos do território que constituem as bases de operação da empresa (SANTOS; SILVEIRA, 2001), um importante caso de uso corporativo do território pôde ser evidenciado, abrindo, assim, a possibilidade para que se pudesse avaliar algumas consequências associadas a atual política de integração do território conduzida pelas companhias aéreas.

\section{INTEGRAÇÃO AÉREA DO TERRITÓRIO BRASILEIRO: O IMPERATIVO DA FLUIDEZ E A REGULAÇÃO NEOLIBERAL DO TERRITÓRIO.}

Ao longo das últimas décadas, um conjunto de transformações na organização produtiva e na regulação política do território brasileiro foram responsáveis por impulsionar o processo de integração aérea nacional. Desde os anos 1970, uma nova divisão territorial do trabalho - marcada pela dispersão geográfica da produção agrícola e industrial e por um processo de centralização do comando das atividades produtivas modernas - culminou numa maior separação territorial das diversas etapas do processo geral de produção, criando assim a necessidade de implantação de sistemas de circulação mais eficientes, que possibilitassem a articulação rápida entre distantes regiões e lugares do país.

De acordo com Silveira (2003, p. 50), o aprofundamento da divisão social e territorial do trabalho e os novos processos de especialização da produção (material e intelectual) nos lugares, intensificaram as relações entre as regiões, sobretudo "(...) entre regiões centrais [ - sede do comando político das atividades modernas - ] e lugares longínquos, onde o processo produtivo, normativo ou financeiro se completa". Segundo Santos e Silveira (2001), tal dissociação territorial das instâncias da produção criou, deste modo, uma maior necessidade de circulação de produtos, serviços, dinheiro, informações e pessoas; um verdadeiro imperativo territorial posto para que o moderno processo geral de produção pudesse se realizar plenamente ${ }^{5}$.

Segundo Cordeiro e Ladeira (1994, p. 283-284), na medida em que se aprofundou no Brasil a dispersão territorial das modernas atividades industriais e agrícolas, e "(...) se reforçou a centralização da gestão e do comando da economia em alguns pontos nodais do espaço (...)", coube especialmente ao sistema de transporte aéreo viabilizar a circulação rápida de empresários, consultores, burocratas, técnicos altamente especializados, entre outros profissionais

\footnotetext{
5 “As especializações do território, do ponto de vista da produção material, assim criadas, são a raiz das complementaridades regionais: há uma nova geografia regional que se desenha, na base da nova divisão territorial que se impõe. Essas complementaridades fazem com que, em consequiência, criem-se necessidades de circulação, que vão tornar-se frenéticas, dentro do território brasileiro, conforme avança o capitalismo; uma especialização territorial que é tanto mais complexa quanto maior o número de produtos e a diversidade de sua produção" (SANTOS, 1994, p. 41).
} 
responsáveis por comandar os lugares incorporados aos modernos "circuitos espaciais de produção"6 (CASTILLO; FREDERICO, 2010).

Segundo ressaltam Cordeiro e Ladeira (1994, p. 284), diferentemente do que se poderia imaginar, apesar das possibilidades de comunicação à distância oferecidas pelas novas tecnologias de informação, a tecnocracia dirigente não se manteve reclusa "(...) nas sedes sociais das grandes empresas" (Idem). Isso porque, conforme afirmam os autores, a "comunicação face-a-face" continuou sendo indispensável para que negócios e tomadas de decisões estratégicas fossem concretizadas, exigindo assim de dirigentes e de outros profissionais altamente especializados, frequentes deslocamentos para os espaços onde se realizam as atividades produtivas modernas.

Desse modo, pode-se dizer que na medida em que se aprofundou a separação territorial das instâncias de produção e de gestão (SILVEIRA, 2003), o papel do sistema aéreo para o funcionamento da moderna organização produtiva no território brasileiro se tornou fundamental, visto que possibilitou a articulação interna do espaço nacional, e assegurou a complementariedade entre as "frações especializadas do território" (CORDEIRO; LADEIRA, 1994). Conforme ressaltam Cordeiro e Ladeira (1994, p. 284), juntamente com os modernos circuitos espaciais de produção, além de produtos e informações, circulam também os homens responsáveis por traçar o destino daqueles espaços integrados às modernas redes de produção.

Desta forma, ao longo das últimas décadas, pôde-se observar a expressiva expansão dos fluxos aéreos no Brasil. Tanto o número de voos domésticos, como o número de passageiros transportados sofreram crescimento exponencial. Somente ao longo das últimas três décadas (de 1990 a 2017), o volume total de passageiros transportados no Brasil sextuplicou, saltando de aproximadamente 14,3 milhões em 1990 (ante 10,6 em 1980), atingindo 70,1 milhões em 2010, e alcançando mais de 90,6 milhões no ano de 2017 (ANAC, 2018a). Segundo a Secretaria de Aviação Civil (2015), do total de passageiros que utilizaram o transporte aéreo no Brasil em 2014, cerca de $50 \%$ afirmaram ter utilizado exclusivamente para fins de trabalho, enquanto os demais declararam ter utilizado por outras razões, como, especialmente, o lazer ${ }^{7}$. Não obstante, pode-se dizer que a expansão recente do sistema de transporte aéreo brasileiro respondeu tanto as crescentes necessidades de deslocamento rápido por longas distâncias criadas pela maior especialização territorial da agricultura, da pecuária, da indústria e dos serviços (consultoria e gestão de negócios), como também resultou do maior dinamismo do turismo e do consumo no país ${ }^{8}$.

Contudo, a nova dinâmica de integração aérea do território brasileiro está associada não apenas às demandas crescentes por circulação rápida - resultantes da implantação da moderna divisão territorial do trabalho -, mas também foi impulsionada pelas políticas neoliberais adotadas pelo Estado brasileiro, as quais levaram a instituição de uma nova lógica de regulação do território nas últimas décadas.

No caso do mercado da aviação doméstica, após décadas de um comando centralizado exercido pelo Estado sobre a instalação de rotas aéreas, o controle de

\footnotetext{
${ }^{6}$ Os circuitos espaciais de produção são definidos pela circulação de bens e produtos entre instâncias de produção (produção, circulação, distribuição e consumo) que encontram-se geograficamente separadas.

${ }^{7}$ Conforme levantamento feito pela Secretaria de Aviação Civil, 49,2\% dos passageiros alegaram que o trabalho havia sido o motivo da viagem, 45,3\% declararam ter realizado a viagem para fins de lazer, 2,4\% por motivo de saúde, e os demais por outras razões. Ressalta-se que tais números sofrem variações conforme cada aeroporto. No caso do aeroporto de Congonhas, por exemplo, localizado no principal centro de negócios do país, a cidade de São Paulo, mais da metade dos passageiros que embarcaram indicaram ser o "trabalho" o motivo da viagem.

${ }^{8}$ Corforme alguns autores, tanto a diminuição do preço médio das passagens (OLIVEIRA, 2012), como o aumento da renda média da população brasileira (CAMILO PERERIRA, 2014), ocorridos a partir dos anos 2000, contribuíram também para o crescimento do número de passageiros transportados pelo o sistema aéreo brasileiro.
} 
tarifas, e a delimitação da área de atuação de cada empresa aérea (mercado regional, nacional ou internacional), um relativo processo de "desregulação do setor aéreo" se estabeleceu a partir, sobretudo, dos anos 1990, momento em que foi concedida as companhias aéreas uma maior autonomia de ação e um maior poder de controle sobre a organização e o funcionamento da malha aérea nacional (BIELSCHOWSKY; CUSTÓDIO, 2011; MALLAGUTTI, 2001; OLIVEIRA, 2012). Conforme esclarece Malagutti (2001, p. 6), como resultado das diretrizes estabelecidas após a V Conferência Nacional de Aviação Comercial, ocorrida no início dos anos 1990,

[...] foi implementado o sistema de liberação monitorado de tarifas aéreas domésticas; foi aberto o mercado doméstico para a entrada de novas empresas, tanto de transporte regular, quanto de transporte não-regular, incluindo regionais e cargueiras, [...]; foi suprimida a delimitação de áreas para a exploração do transporte regional e a exclusividade desfrutada, dentro das mesmas [áreas], por algumas empresas; flexibilizaram-se os parâmetros para a concessão de linhas, foram designadas novas empresas nacionais para explorar o transporte aéreo internacional; foi admitida a criação e o licenciamento de um novo tipo de empresa, destinada à exploração do transporte aéreo não-regular de cargas e passageiros, na modalidade de "charter", e foi enfim, como decorrência de todas essas medidas, aumentada a oferta aos usuários.

Com o processo de "desregulação" do mercado brasileiro de aviação doméstica as empresas passaram a dispor de uma maior autonomia para criar e extinguir rotas aéreas, regular tarifas, estabelecer preços de passagens, e (re)definir suas escalas territoriais de atuação. Em suma, uma nova forma de regulação do sistema aéreo nacional se estabeleceu - uma regulação neoliberal - a qual passou a submeter a dinâmica de integração aérea do território brasileiro às políticas e estratégias econômicas das empresas, e sujeitou as possibilidades de incorporação dos lugares ao sistema de circulação aéreo nacional à lógica e aos propósitos do mercado.

Desse modo, motivado pelas demandas crescentes por transporte aéreo estabelecidas no território brasileiro, e estimulado por um regime regulatório extremamente favorável a atuação mais livre das empresas, observou-se, a partir do final dos anos 1990, um verdadeiro processo de ampliação dos fluxos aéreos nacionais. Enquanto entre 1980 e 1990 o número de voos domésticos no Brasil sofreu uma modesta evolução, passando de 209.000 para 245.200 voos ao ano, em 2000 esse número havia saltado para expressivos 693.389 voos, e no ano de 2017 registrou a marca de 805.718 voos realizados no país (ANAC, 2018a). Conforme destacou a Agência Nacional de Aviação Civil (ANAC, 2017), no ano de 2017, do número total de passageiros que realizaram viagens interestaduais de longa distância no Brasil, 67,5\% já utilizaram o sistema de transporte aéreo regular.

Assim, condicionado pela nova organização produtiva do território; favorecido pela infraestrutura aeroportuária disponível; influenciado pelas novas demandas por transporte aéreo estabelecidas no país; e, estimulado pelas distintas oportunidades de ganhos econômicos oferecidos pelos lugares às empresas aéreas, os fluxos aéreos nacionais se ampliaram, e a rede de transporte aéreo brasileira passou a articular, com maior intensidade, as diferentes regiões do país (Mapas 1 e 2).

Contudo, apesar do maior grau de integração aérea do território brasileiro, desigualdades regionais relacionadas à densidade dos fluxos aéreos mantiveram-se ainda bastante presentes. Basta dizer que de um total de 877 pares de ligações que constituíam a malha aérea nacional em 2010, apenas 24 destes respondiam por $50 \%$ 
do total de passageiros transportados no país (Tabela 1), tendo destaque especial as ligações entre São Paulo e as cidades do Rio de Janeiro, Brasília, Porto Alegre, Salvador, Belo Horizonte e Curitiba, responsáveis por mais de $25 \%$ do total de passageiros transportados (IBGE, 2013).
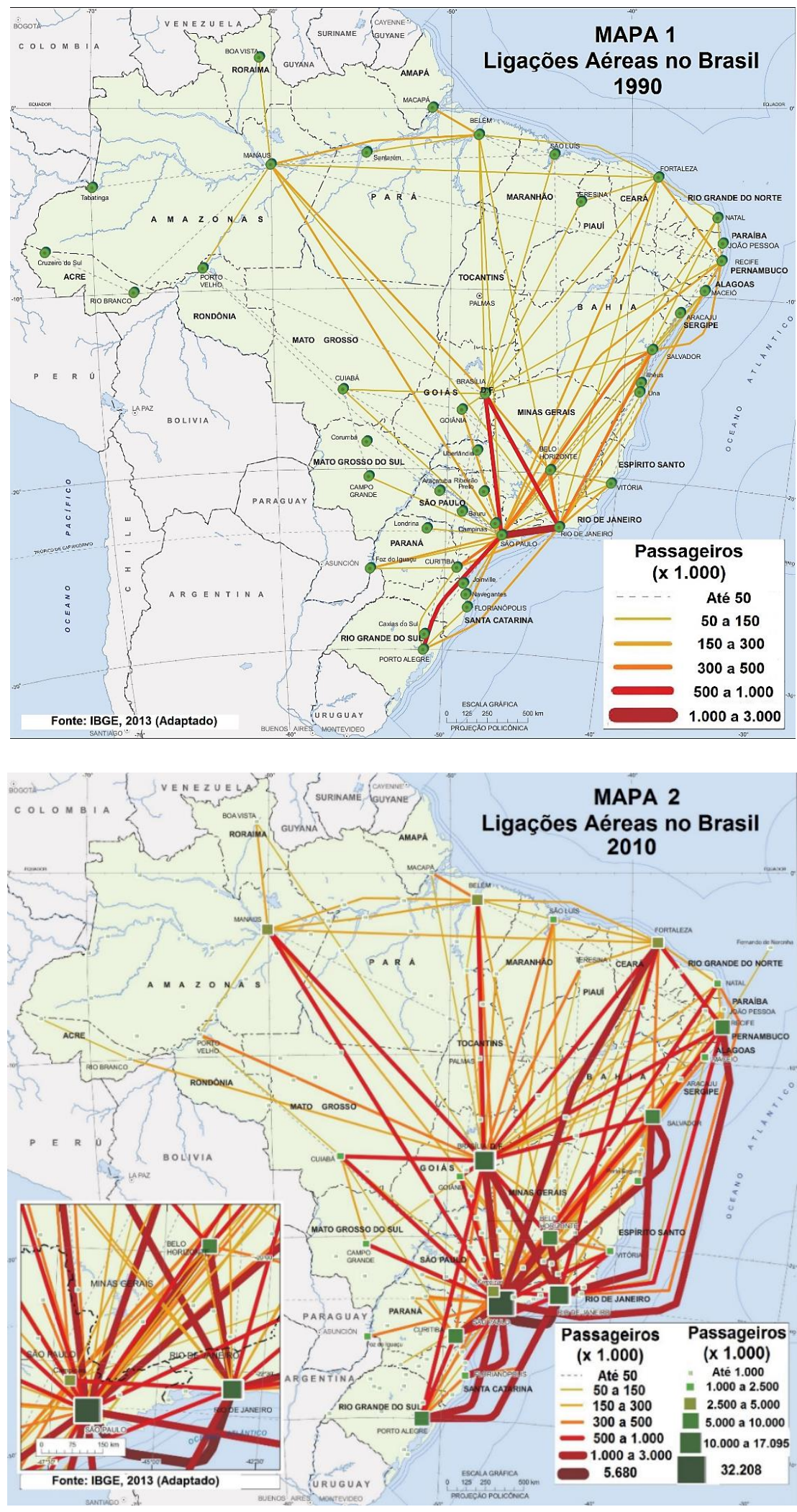
TABELA 1 - Movimento aéreo de passageiros, segundo os municípios que correspondem aos 50\% maiores pares de ligação - 2010.

\begin{tabular}{|l|c|c|}
\hline \multirow{2}{*}{$\begin{array}{l}\text { Municípios que correspondem aos 50\% } \\
\text { maiores pares de ligação }\end{array}$} & Passageiros & (\%) Acumulado \\
\cline { 2 - 3 } & 5.680 .873 & 7,9 \\
\hline São Paulo - Rio de Janeiro & 3.006 .422 & 12,1 \\
\hline São Paulo - Brasília & 2.619 .204 & 15,8 \\
\hline São Paulo - Porto Alegre & 2.270 .250 & 22,0 \\
\hline São Paulo - Salvador & 2.239 .153 & 25,2 \\
\hline São Paulo - Belo Horizonte & 2.236 .264 & 27,6 \\
\hline São Paulo - Curitiba & 1.760 .321 & 29,8 \\
\hline Rio de Janeiro - Brasília & 1.574 .592 & 31,7 \\
\hline São Paulo - Recife & 1.365 .686 & 33,4 \\
\hline São Paulo - Florianópolis & 1.224 .394 & 35,0 \\
\hline Rio de Janeiro - Salvador & 1.147 .735 & 36,6 \\
\hline Rio de Janeiro - Belo Horizonte & 1.141 .440 & 38,0 \\
\hline São Paulo - Fortaleza & 1.018 .711 & 39,3 \\
\hline Rio de Janeiro - Porto Alegre & 941.428 & 40,6 \\
\hline Brasília - Belo Horizonte & 930.819 & 41,8 \\
\hline São Paulo - Goiânia & 811.261 & 42,9 \\
\hline São Paulo - Vitória & 795.867 & 44,0 \\
\hline Rio de Janeiro - Recife & 787.633 & 45,1 \\
\hline Rio de Janeiro - Vitória & 774.535 & 46,1 \\
\hline Rio de Janeiro - Campinas & 726.530 & 47,0 \\
\hline Brasília - Salvador & 692.148 & 48,0 \\
\hline Rio de Janeiro - Curitiba & 686.289 & 47.947 \\
\hline São Paulo - Natal & 650.344 & \\
\hline Brasília - Fortaleza & & \\
\hline Salvador - Recife & & \\
\hline Fonte: IBGE, 2013. & \\
\hline
\end{tabular}

Fonte: IBGE, 2013.

Reproduzindo, de certo modo, a hierarquia da rede urbana brasileira, os fluxos aéreos convergiam sobretudo para as grandes metrópoles do país, isto é, para os principais "centros de gestão do território"' (CORREA, 1996), com destaque especial para São Paulo, metrópole que exerce centralidade tanto na rede urbana como na malha aérea nacional. De acordo com Hervé Terry (2003), no ano de 2001, São Paulo já se conectava por via aérea a outras 146 localidades distribuídas por 25 estados brasileiros, um número que representava quase o dobro de ligações apresentadas pelo Rio de Janeiro (78), e se constituía em um valor bem superior àqueles apresentados por outras grandes cidades brasileiras, como Salvador (55), Brasília (54), Manaus (51), Fortaleza (44), Belém (43), Porto Alegre (41), Campinas (41) e Recife (40). Assim, pode-se dizer que a cidade de São Paulo já se interligava a um conjunto amplo de lugares e regiões do país, reafirmando, dessa maneira, sua posição na divisão territorial trabalho e na rede urbana brasileira como "metrópole onipresente", isto é, como "metrópole irrecusável para todo o território brasileiro"10 (SANTOS, 1994, p. 90).

\footnotetext{
${ }^{9}$ Segundo Côrrea (1996, p. 25), "o centro de gestão do território caracteriza-se, em realidade, por ser um centro onde tomamse decisões e fazem investimentos de capital que afetam direta e indiretamente amplo espaço. Controlam assim, a organização espacial de um dado espaço, influenciando a gênese e a dinamica produtiva (...), assim como a política local e o modo de inserção das cidades na rede urbana sob seu controle".

${ }^{10}$ Conforme Santos (1994, p. 90), as "atividades modernas presentes em diversos pontos do país necessitam se apoiar em São Paulo para um número crescente de tarefas. São Paulo fica presente em todo o território brasileiro graças a esses novos nexos, geradores de fluxos de informação indispensáveis ao trabalho produtivo. [...] É desse modo que São Paulo se impõe como metrópole onipresente, e por isso mesmo, e ao mesmo tempo, como metrópole irrecusável para todo o território brasileiro".
} 
Por sua vez, apesar da concentração dos fluxos aéreos junto às grandes cidades e capitais de estados, a atual dinâmica de integração aérea do território brasileiro vem também sendo marcada por um relativo processo de capilarização. Efeito da desconcentração das modernas atividades produtivas no território; dos novos processos de valorização econômica dos lugares; e, das novas possibilidades abertas às empresas de exploração econômica do sistema de transporte aéreo nacional, ampliou-se a circulação aérea junto, principalmente, às cidades regionais do interior do país, de modo que tais lugares passaram a ser incorporados, com maior intensidade, às redes de circulação rápida do território nacional. Entre os anos de 2000 e 2017, o número de lugares que recebiam mais de 50.000 passageiros ao ano no Brasil cresceu de 57 para 76, e o número de trechos aéreos (pares de ligações) que transportavam mais de 50.000 passageiros ao ano, saltou de 107 para 219 ligações durante o mesmo período (ANAC, 2017b) (Tabela 2).

\section{TABELA 2 - Dinâmica de expansão e concentração dos fluxos aéreos no Brasil entre} 2000 e 2017.

\begin{tabular}{|l|c|c|c|}
\hline & 2000 & 2010 & 2017 \\
\hline $\begin{array}{l}\text { Total de aeroportos que movimentaram mais de 50.000 passageiros } \\
\text { (embarque + desembarque). }\end{array}$ & 57 & $\mathbf{6 7}$ & $\mathbf{7 6}$ \\
\hline $\begin{array}{l}\text { Total de ligações aéreas que transportaram mais de 50.000 } \\
\text { passageiros. }\end{array}$ & $\mathbf{1 0 7}$ & $\mathbf{1 9 3}$ & $\mathbf{2 1 9}$ \\
\hline $\begin{array}{l}\text { Total de aeroportos que realizaram mais de 100 pousos e } \\
\text { decolagens. }\end{array}$ & $\mathbf{1 6 1}$ & $\mathbf{1 3 4}$ & $\mathbf{1 1 2}$ \\
\hline
\end{tabular}

Fonte: ANAC, 2018b.

Entretanto, essa atual expansão territorial do sistema de transporte aéreo brasileiro vem se constituindo num fenômeno aparentemente antagônico, visto que o crescimento do número de voos e de passageiros transportados no país ocorreu, paralelamente, a uma redução do número absoluto de lugares alcançados regularmente por voos domésticos. Enquanto no ano de 2000 registrou-se 161 lugares com mais de 100 pousos e decolagens realizados, em 2017 apenas 112 lugares alcançaram aquela marca no país (ANAC, 2018b) (Tabela 2). Em síntese, apesar de ter ocorrido um expressivo crescimento dos fluxos aéreos ao longo das últimas duas décadas, estes passaram a se concentrar progressivamente em um número menor de lugares. Desse modo, pode-se dizer que ocorreu um processo de expansão territorialmente seletiva e concentrada dos fluxos aéreos no Brasil.

Assim, sob os impulsos dos novos processos de valorização dos lugares e por intermédio das estratégias mercantis de uso do território estabelecidas pelas empresas, a atual fase de integração aérea do território brasileiro se estabeleceu, ganhando forma e conteúdo específicos. Mesmo com a expansão do sistema de transporte aéreo nacional, a fluidez do território brasileiro apresenta desigualdades regionais marcantes, consequência tanto das diferentes possibilidades de ação oferecidas por cada lugar (disponibilidade de infraestrutura aeroportuária, existência de demanda local por transporte aéreo, etc.), como da atuação territorialmente seletiva das companhias aéreas operantes no país. Desse modo, é, pois, em busca da compreensão da lógica que rege a atual dinâmica de integração aérea do território nacional que, a seguir, analisaremos a territorialidade e avaliaremos as estratégias de uso do território que orientam a atuação das empresas aéreas no Brasil. 


\section{TERRITÓRIO E MERCADO: OLIGOPÓLIO E TERRITORIALIDADE DAS EMPRESAS AÉREAS NO BRASIL.}

A atual dinâmica de integração aérea do território brasileiro é caracterizada não apenas pela "desregulação do setor aéreo" e pela "expansão-concentrada" dos fluxos aéreos nacionais, mas também é marcada pela consolidação de um verdadeiro processo de oligopolização do mercado e do território promovido por algumas grandes companhias. Conforme dados disponibilizados pela ANAC (2018a), apenas quatro empresas controlavam $99 \%$ do mercado brasileiro de voos domésticos no ano de 2017, sendo que GOL Linhas Aéreas S/A, LATAM Linhas Aéreas S/A, AZUL Linhas Aéreas e AVIANCA respondiam, respectivamente, por 33,6\%, 31,0\%, 22,8\%, e 11,7\% do volume total de passageiros transportados no país.

Como é de amplo conhecimento, os oligopólios configuram-se como uma estrutura em que poucas corporações detém o controle sobre a produção e/ou oferta de determinado produto ou serviço e, desta forma, essas empresas conseguem estabelecer barreiras ao ingresso de outras, isto é, inibem a concorrência e garantem as condições que permitem a elas obterem os maiores lucros possíveis no mercado em que atuam. Contudo, conforme destaca Santos (1994, p. 89), "não é demais lembrar que mercado e território são sinônimos"11, e, neste sentido, podemos dizer que o controle centralizado exercido por algumas empresas sobre o mercado de aviação comercial se constitui, também, numa modalidade de exercício de comando sobre a organização da rede aérea nacional e sobre as possibilidades de integração aérea do território. Conforme esclarece Corrêa (1992, p. 35),

$\mathrm{Na}$ fase atual do capitalismo as grandes corporações multifuncionais e multi-localizadas desempenham papel fundamental na organização espacial, exercendo determinado controle sobre amplo e diferenciado território. Este controle constitui-se em um dos meios através do qual a corporação garante com máxima eficiência a acumulação de capital e a reprodução de suas condições de produção.

No Brasil, nos últimos anos, pôde-se observar que algumas grandes empresas aéreas se apropriaram de maneira privilegiada do mercado de aviação doméstica, passando a promover uma integração aérea do território nacional segundo suas estratégias particulares de acumulação de capital, e conforme as possibilidades de ação oferecidas pelos distintos lugares e regiões do país. Em resumo, com a demanda crescente por circulação rápida instituída, não apenas o território brasileiro se consolidou como um relevante mercado que passou a ser cobiçado e explorado com afinco por grandes companhias, como também pode-se dizer que as empresas aéreas passaram a usar o território como "recurso" (SANTOS, et al., 2000) visando realizar seus interesses corporativos.

Diante disso, a análise da malha aérea nacional se constitui num instrumento importante para a observação dos usos econômicos do território realizados pelas

\footnotetext{
${ }^{11}$ Vale novamente destacar que, para Milton Santos et al. (2000), o território se constitui no espaço em que se encontram diferentes agentes sociais e, portanto, coexistem distintas lógicas de uso do território. Desta forma, pode-se dizer que, segundo os interesses e os propósitos de cada agente, o território assume diferentes significados. Enquanto, por exemplo, o território pode ser definido sobretudo como recurso para as grandes empresas, isto é, um trunfo e uma oportunidade para a realização dos seus negócios e a conquista de seus interesses econômicos, para outros agentes o território pode assumir outros sentidos, e se definir sobretudo como abrigo, isto é, como refúgio e condição para a existência e a sobrevivência de determinados grupos sociais. Desta maneira, esclarece-se que diante dos diversos significados que o território assume, ele também pode ser visto como mercado, haja visto que "(...) é neste espaço que um mercado hierarquizado e articulado pelas firmas hegemônicas, nacionais e estrangeiras comandam o território com apoio do Estado" (SANTOS, 1994, p. 89).
} 
companhias aéreas, bem como para apreender suas distintas estratégias de valorização e apropriação do território.

Sendo assim, ao se analisar a malha aérea brasileira, pôde-se notar, de modo geral, que enquanto as maiores e mais influentes companhias se consolidam como aquelas que detêm a força e a capacidade de se inserir nos maiores aeroportos e operar as rotas mais movimentadas (e rentáveis) do país - frequentemente os trechos que interligam as grandes metrópoles nacionais e estas aos principais centros regionais - às empresas de menor porte resta, comumente, explorar apenas os aeroportos e as rotas que interligam as cidades de menor porte e menor fluxo de passageiros (Gráficos 1, 2 e 3).

\section{GRÁFICO 1 - Ranking dos 20 aeroportos que concentram o maior fluxo de} passageiros (embarque + desembarque) no Brasil em 2017 (Voos domésticos).

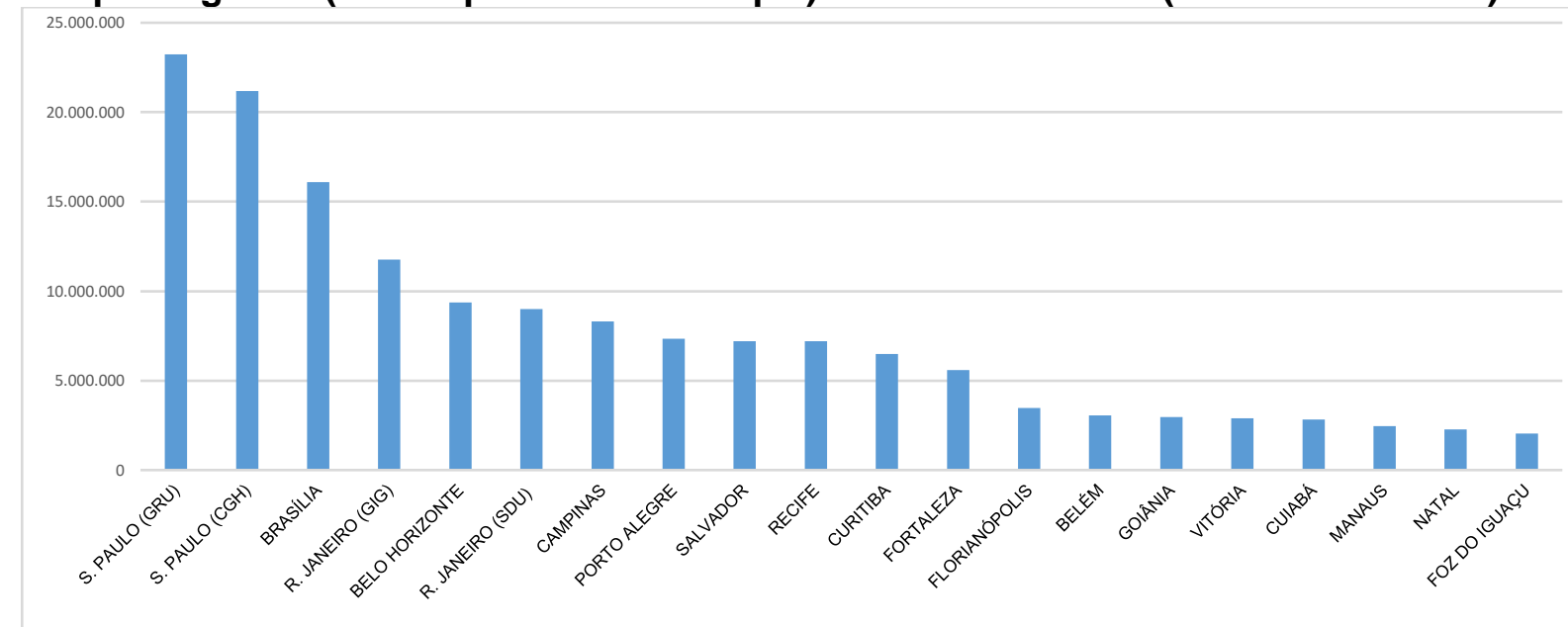

\section{GRÁFICO 2 - Número de voos (decolagens regulares) controlados por companhia} aérea nos 20 aeroportos mais movimentados do Brasil - 2017.

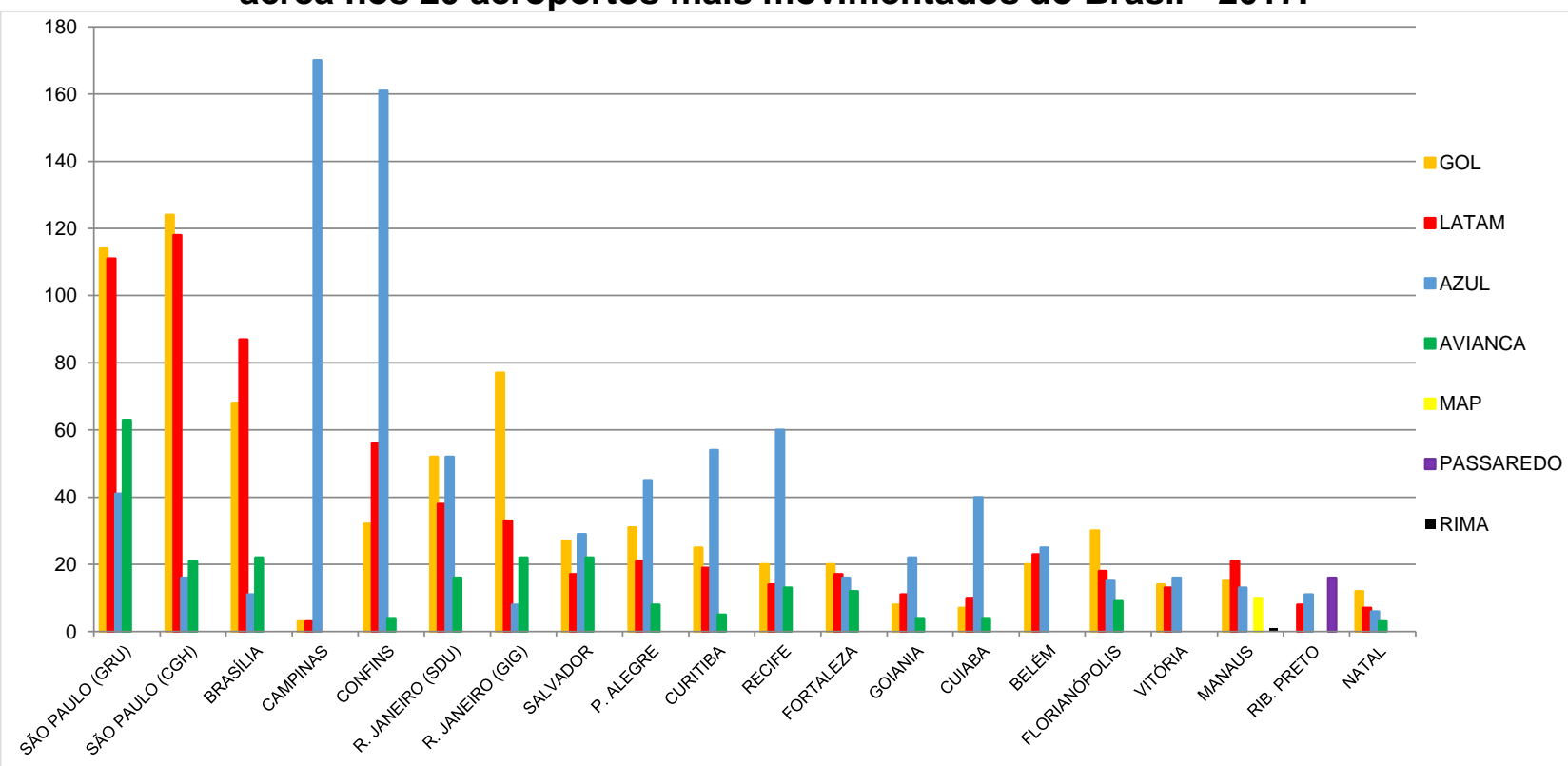

Fonte: ANAC, 2018c. 


\section{GRÁFICO 3 - Ranking dos pares de ligações aéreas que movimentaram $50 \%$ do total de passageiros transportados no Brasil em 2017. Participação por empresa.}

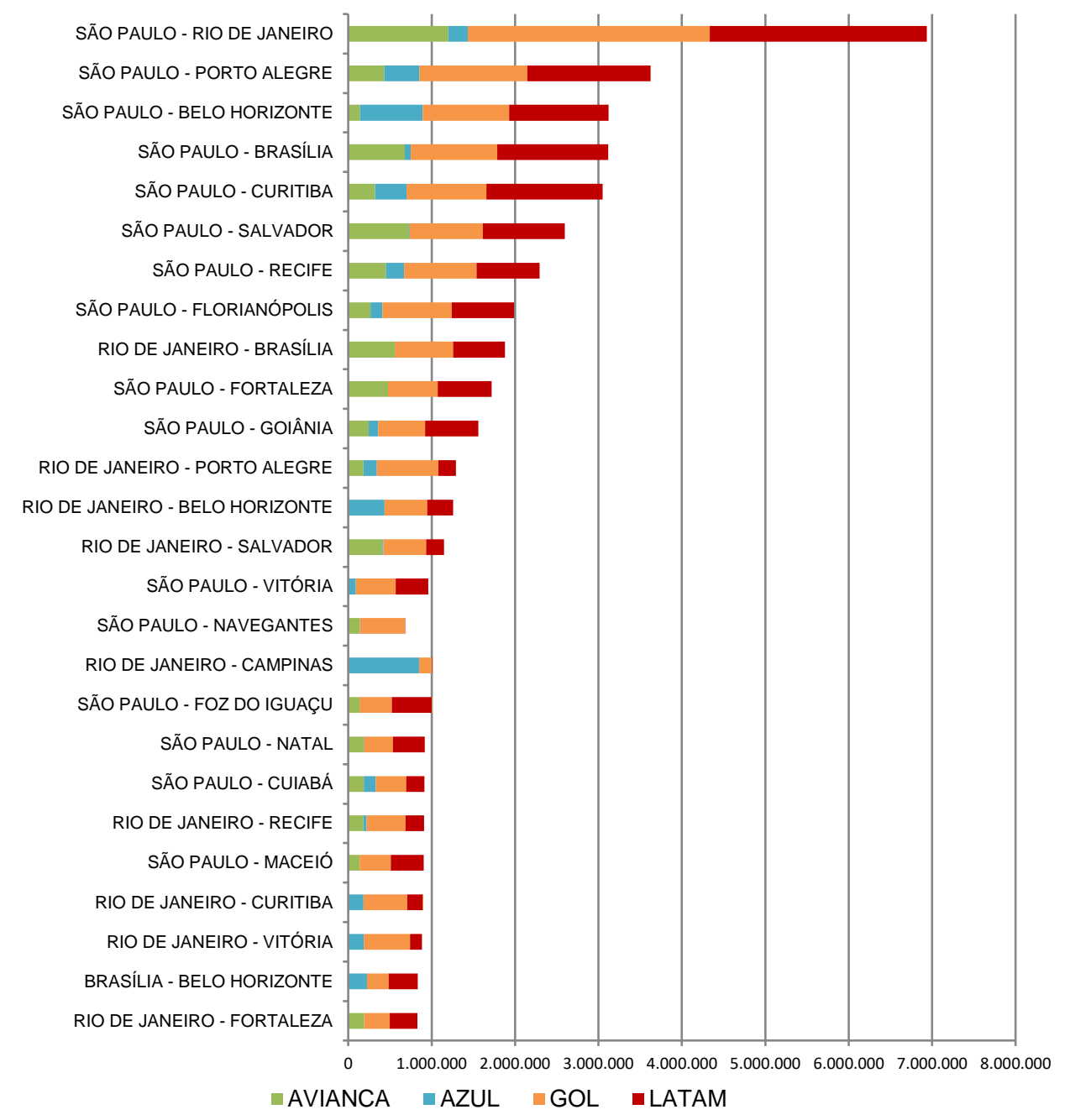

Fonte: ANAC, 2018b.

Por mais breve que pudesse ser a apreciação que qualquer pessoa fizesse dos painéis eletrônicos que sinalizassem as partidas e chegadas de voos domésticos nos maiores aeroportos brasileiros em 2017, podia-se facilmente constatar o predomínio absoluto das companhias aéreas Gol, Latam, Azul e Avianca, no controle da oferta dos voos que interligavam os maiores centros urbanos brasileiros, com destaque especial para as rotas entre as cidades de São Paulo, Rio de Janeiro, Brasília, Belo Horizonte, Campinas, Salvador, Recife, Fortaleza, Porto Alegre, Curitiba, Florianópolis, Goiânia e Vitória (Gráfico 3).

Contudo, ao se analisar, com maior acuidade a atuação territorial das companhias aéreas mais proeminentes do país, podia-se também notar que elas possuíam territorialidades distintas, assim como realizavam um uso extremamente seletivo do território. Empresas como Gol, Latam e Avianca, por exemplo, ainda que possuíssem um grande alcance territorial - dispondo de uma malha aérea que se estendia por diferentes regiões do país (Figuras 1, 2 e 3) - se caracterizavam por atuar de forma mais incisiva nos trechos da rede aérea brasileira que concentravam o maior fluxo de passageiros, isto é, especialmente nas ligações entre São Paulo e Rio de Janeiro, e entre estas metrópoles e às cidades de Brasília, Belo Horizonte, Curitiba, Porto Alegre, Salvador, Recife, Florianópolis e outras grandes capitais de estados 
(Gráficos 2 e 3). Em suma, através da apropriação privilegiada que realizavam de aeroportos e da malha aérea brasileira, as referidas companhias dispunham do poder de comandar a maioria dos voos ofertados entre os maiores centros urbanos do país, controlando, desse modo, os trechos da malha aérea que correspondiam ao maior mercado da aviação comercial do Brasil (50\% do total de passageiros transportado em 2017).

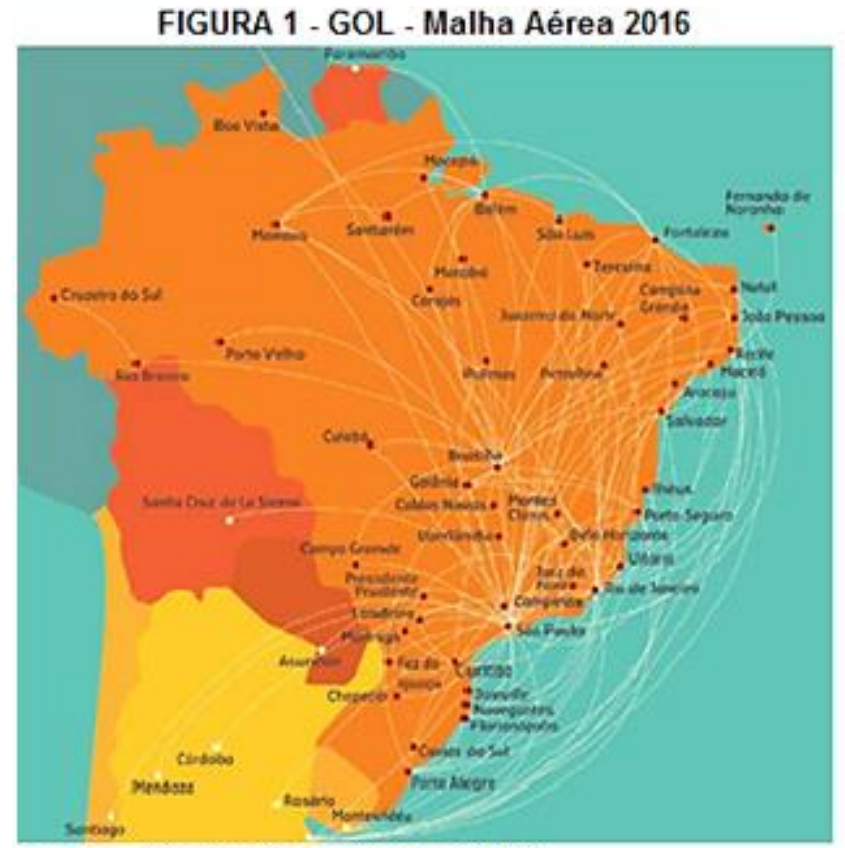

Fontes: Aviação Comercial.Net (2018)

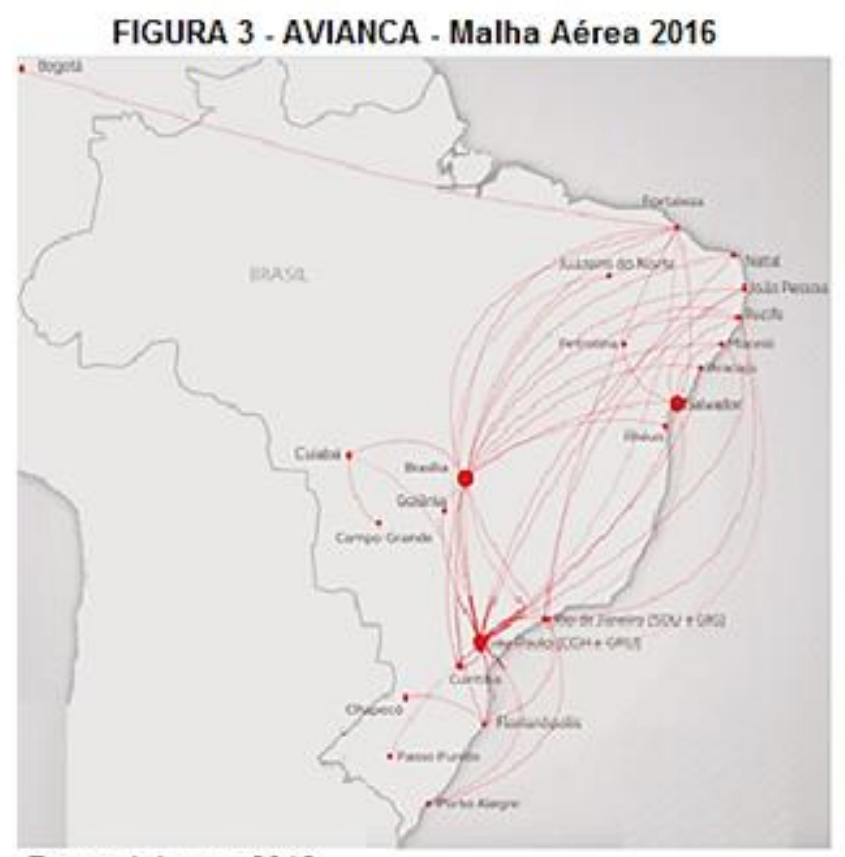

Fonte: Avianca, 2016.
FIGURA 2 - LATAM - Malha Aérea 2016

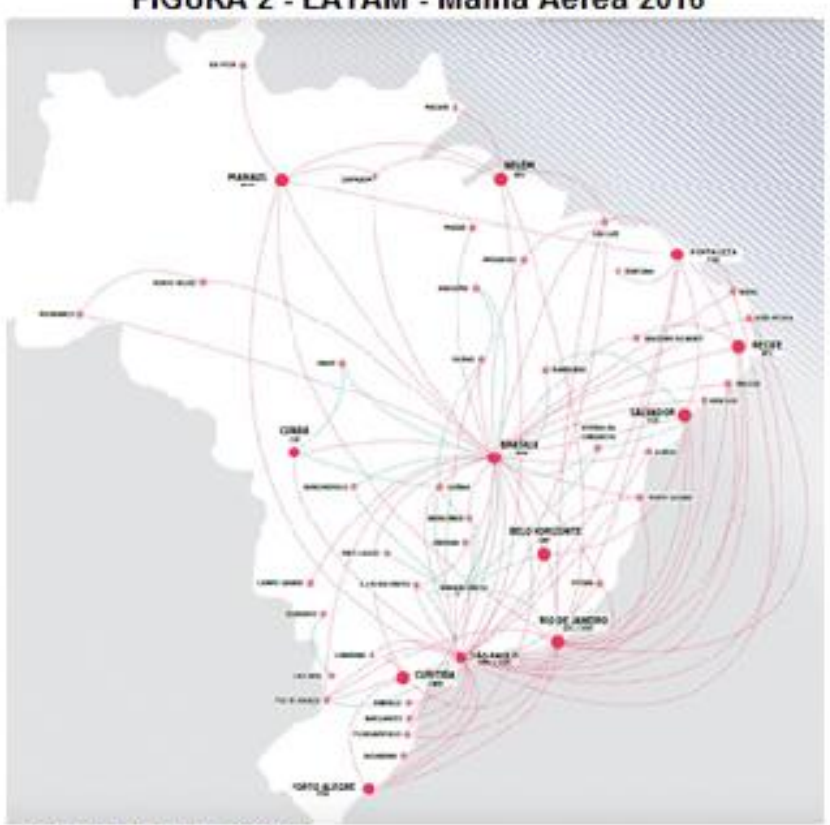

Fonte: Latam, 2016.

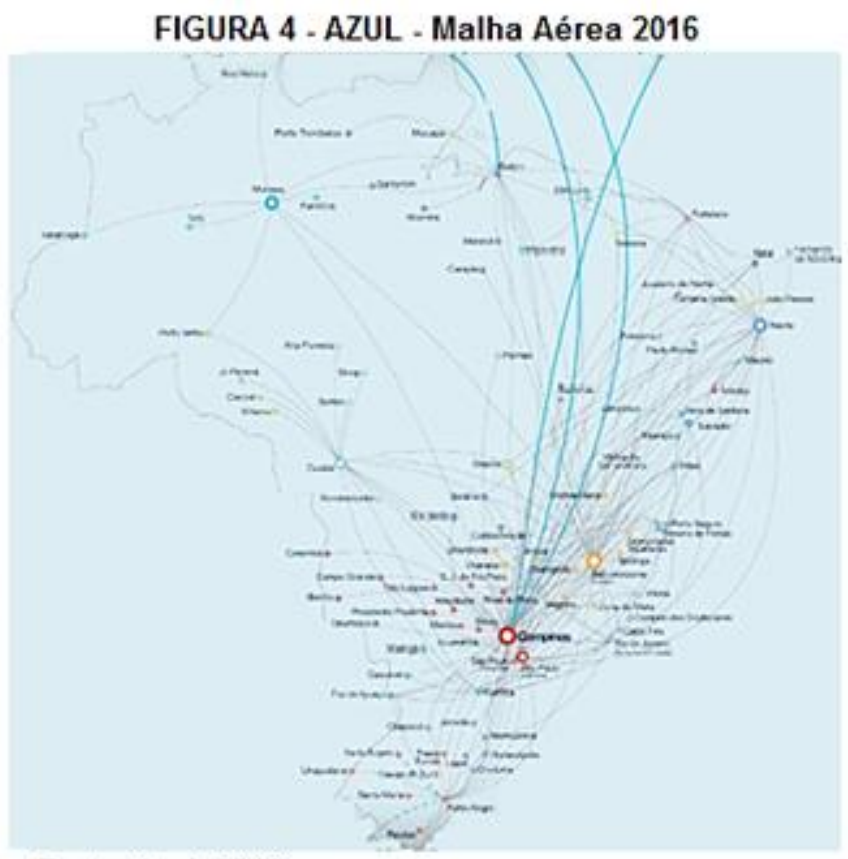

Fonte: Azul, 2016.

Por sua vez, a Azul Linhas Aéreas se constituía numa companhia cuja atuação territorial se distinguia, em certa medida, das empresas anteriormente mencionadas. Isso porque, além de sua escala nacional de atuação uma outra característica lhe era peculiar: a ampla capilaridade territorial da malha aérea estabelecida pela empresa (Figura 4). Vale destacar que enquanto no ano de 2016, Gol, Latam e Avianca 
operaram voos em 58, 49 e 28 aeroportos brasileiros, respectivamente, a Azul atuou em 109 (ANAC, 2008a). Apesar de ser limitada sua inserção nos maiores aeroportos (Guarulhos-SP, Congonhas-SP, Brasília-DF, Santos Dumont - RJ e Galeão - RJ) e nos principais eixos de circulação aérea do país (São Paulo - Rio de Janeiro, São Paulo - Porto Alegre, São Paulo - Brasília) (Gráficos 1, 2 e 3), a empresa contribuiu para uma relativa reconfiguração da malha aérea brasileira.

Tal reconfiguração pôde ser constatada, por um lado, pelo papel que a companhia atribuiu a Campinas; cidade do interior paulista que passou a desempenhar maior centralidade na malha aérea nacional ao se constituir no principal polo emissor dos fluxos aéreos comandados pela empresa (Gráficos 1 e 2$)^{12}$. Por outro lado, a Azul foi responsável por aumentar, significativamente, o número de cidades regionais que passaram a dispor de voos comerciais regulares, levando estes lugares a serem incorporados, mais intensamente, às redes de circulação rápida do território brasileiro. Através de uma estratégia peculiar de uso econômico do território, a companhia ampliou a ligação direta entre espaços não-metropolitanos, tendo em muitos casos o controle abrangente da exploração de muitas destas rotas estabelecidas entre capitais de estados e/ou cidades regionais (Gráfico 4).

\section{GRÁFICO 4 - Pares de ligações que movimentaram pouco mais de 50 mil passageiros no ano de 2017. Participação por empresa.}

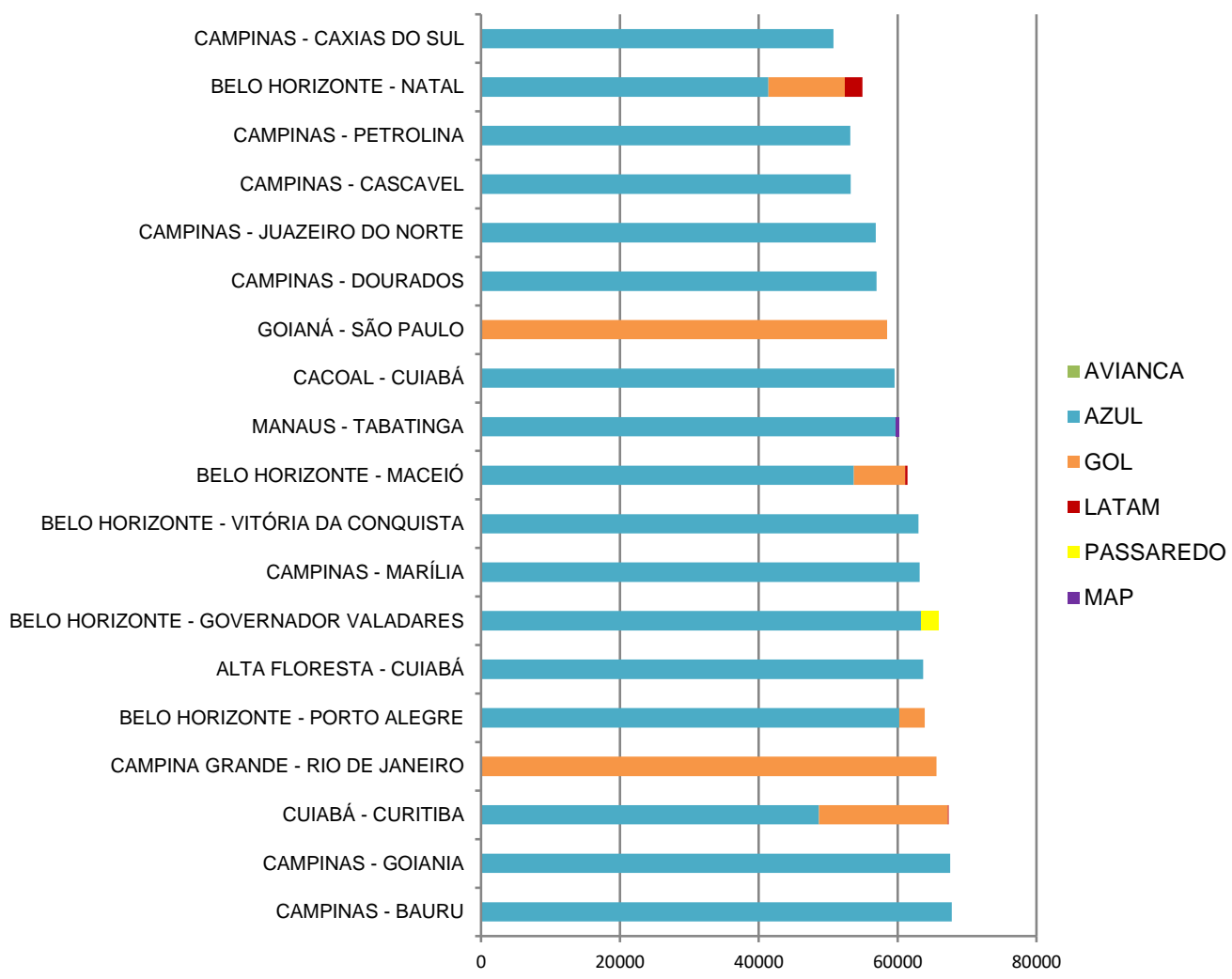

Fonte: ANAC, 2018b.

Por outro lado, enquanto as grandes companhias aéreas conseguiam realizar uma apropriação privilegiada e seletiva do território, restava sobretudo às poucas companhias de aviação comercial de pequeno e médio portes existentes no país, tais

\footnotetext{
12 Desde o início das operações da Azul em 2008, o aeroporto de Viracopos, situado em Campinas, viu aumentar em mais de nove vezes $(9,4)$ seu fluxo de passageiros (embarques + desembarques), o que o levou da $20^{\circ}$ para a $7^{\circ}$ posição no ranking dos aeroportos mais movimentados do país, entre os anos de 2008 e 2017.
} 
como MAP Linhas Aéreas, ASTA Linhas Aéreas e PASSAREDO Linhas Aéreas, por exemplo, atuar especialmente no âmbito da aviação regional, operando linhas com número reduzido de passageiros, realizando percursos de menor extensão (interligando cidades dentro de um estado ou entre estados vizinhos), enfim, em outras palavras, atuar nos interstícios, ou melhor, nas "brechas territoriais" deixadas pelas grandes empresas (Tabela 3 e Figuras 5, 6 e 7). No ano de 2017, apenas 1\% do total de passageiros que utilizaram o sistema aéreo brasileiro foi transportado por companhias de médio ou pequeno porte, sendo que Passaredo e Map Linhas Aéreas responderam, juntas, por $0,7 \%$ do total de passageiros transportados no país.

TABELA 3 - Ranking das ligações aéreas e número de passageiros transportados pelas principais companhias aéreas de pequeno e médio porte do Brasil - 2017.

\begin{tabular}{|c|c|c|c|c|}
\hline \multirow{23}{*}{$\begin{array}{l}\text { Ranking das } \\
\text { principais } \\
\text { ligações }\end{array}$} & PASSAREDO & $\begin{array}{l}\text { Passageiros } \\
\text { transportados }\end{array}$ & MAP Linhas Aéreas & $\begin{array}{l}\text { Passageiros } \\
\text { transportados }\end{array}$ \\
\hline & SÃO PAULO - RIBEIRÃO PRETO & 136.442 & MANAUS - PARINTINS & 15.342 \\
\hline & $\begin{array}{l}\text { SALVADOR - VITÓRIA DA } \\
\text { CONQUISTA }\end{array}$ & 74.354 & BELÉM - ALTAMIRA & 10.928 \\
\hline & BRASÍLIA - RIBEIRÃO PRETO & 66.127 & $\begin{array}{l}\text { MANAUS - SÃO GABRIEL } \\
\text { DA CACHOEIRA }\end{array}$ & 9.939 \\
\hline & $\begin{array}{c}\text { RIO DE JANEIRO - RIBEIRÃO } \\
\text { PRETO }\end{array}$ & 52.394 & MANAUS - ITAITUBA & 9.511 \\
\hline & $\begin{array}{c}\text { BELO HORIZONTE - RIBEIRÃO } \\
\text { PRETO }\end{array}$ & 43.165 & BELÉM - ITAITUBA & 8.540 \\
\hline & $\begin{array}{c}\text { SÃO PAULO - VITÓRIA DA } \\
\text { CONQUISTA }\end{array}$ & 35.163 & EIRUNEPÉ - TABATINGA & 8.345 \\
\hline & SALVADOR - BARREIRAS & 24.769 & MANAUS - CARAUARI & 4.620 \\
\hline & BRASÍLIA - BARREIRAS & 20.823 & BELÉM - ORIXIMINÁ & 4.420 \\
\hline & GOIÂNIA - RIBEIRÃO PRETO & 17.975 & MANAUS - ORIXIMINÁ & 4.195 \\
\hline & GOIÂNIA - ARAGUAÍNA & 14.116 & MANAUS - ALTAMIRA & 3.662 \\
\hline & $\begin{array}{l}\text { RIBEIRÃO PRETO - } \\
\text { RONDONÓPOLIS }\end{array}$ & 13.127 & MANAUS - LÁBREA & 3.095 \\
\hline & CASCAVEL - SÃO PAULO & 11.982 & SANTARÉM - ORIXIMINÁ & 2.866 \\
\hline & ARAGUAÍNA - PALMAS & 11.645 & MANAUS - COARI & 2.600 \\
\hline & $\begin{array}{c}\text { RIBEIRÃO PRETO - SÃO JOSÉ } \\
\text { DO RIO PRETO }\end{array}$ & 10.813 & MANAUS - TEFÉ & 2.593 \\
\hline & RONDONÓPOLIS - SÃO PAULO & 8.791 & SANTARÉM - ALTAMIRA & 2.439 \\
\hline & $\begin{array}{l}\text { RIBEIRÃO PRETO - TRÊS } \\
\text { LAGOAS }\end{array}$ & 6.939 & MANAUS - BARCELOS & 2.336 \\
\hline & GOIANIA - PALMAS & 6.696 & ALTAMIRA - ITAITUBA & 1.013 \\
\hline & BRASÍLIA - SINOP & 6.136 & BELÉM - SANTARÉM & 979 \\
\hline & PALMAS - RIBEIRÃO PRETO & 4.401 & MANAUS - SANTARÉM & 828 \\
\hline & BRASÍLIA - SALVADOR & 4.014 & ITAITUBA - PARINTINS & 521 \\
\hline & Demais ligações & 54.385 & Demais ligações & 3.114 \\
\hline & Total & 625.681 & Total & 102.523 \\
\hline $\begin{array}{l}\text { Total (\%) } \\
\text { nacional } \\
\text { transportado }\end{array}$ & $0,6 \%$ & & $0,1 \%$ & \\
\hline
\end{tabular}

Fonte: ANAC, 2018b. 

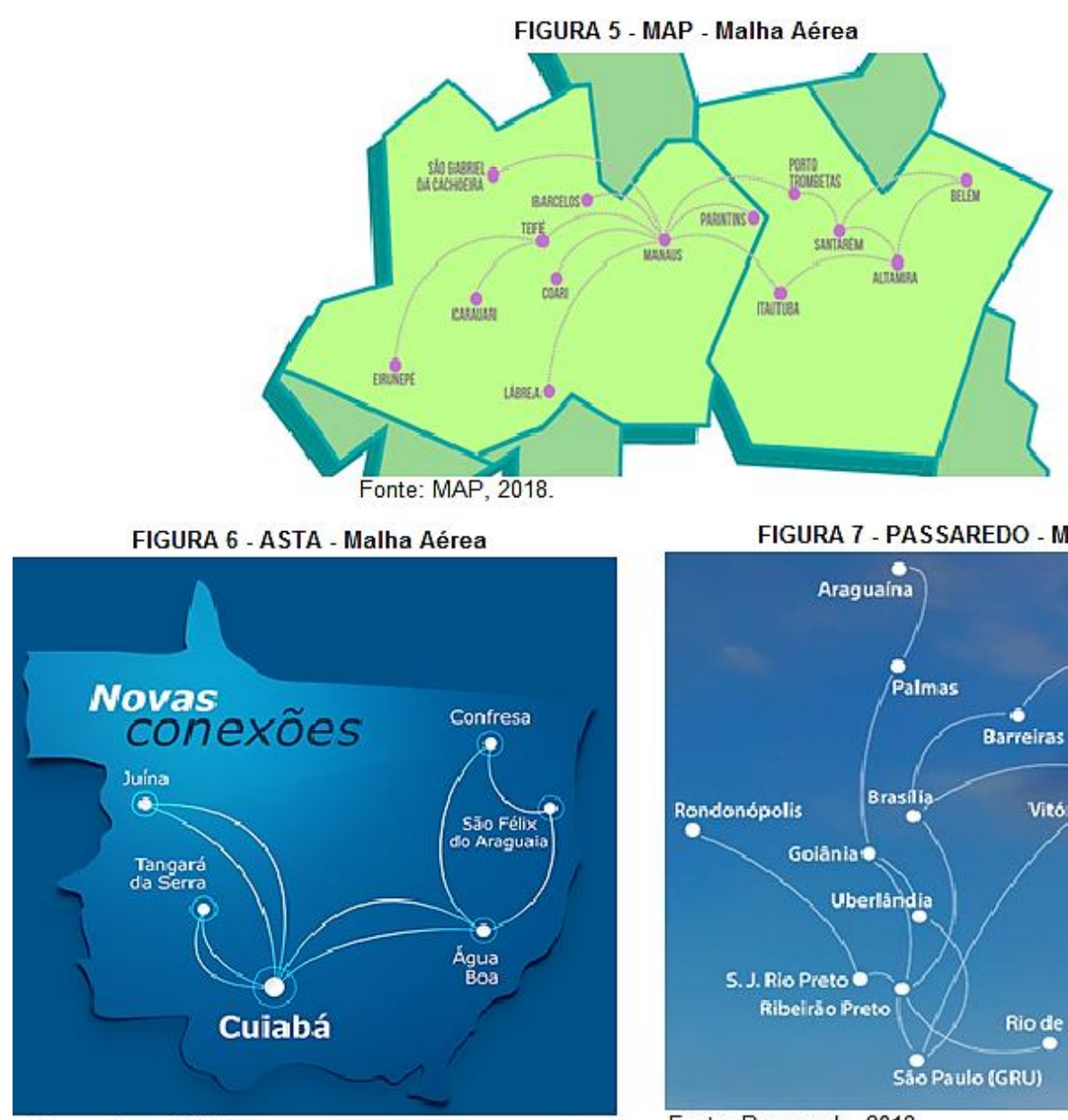

FIGURA 7 - PASSAREDO - Malha Aérea

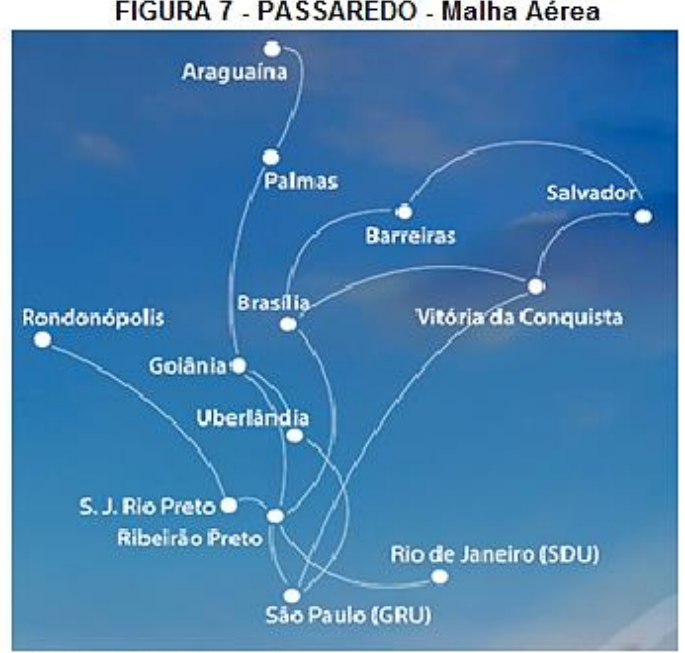

Fonte: Passaredo, 2018

A avaliação da malha aérea nacional e a análise da territorialidade diferencial das companhias aéreas operantes no Brasil revelam uma verdadeira segmentação do território enquanto mercado, bem como uma apropriação privilegiada de alguns lugares e determinadas parcelas do território nacional pelas grandes empresas. Tratase, em certos casos, de um domínio abrangente na exploração de determinados aeroportos e trechos da malha aérea nacional realizado por poucas companhias, configurando verdadeiros oligopólios territoriais (SANTOS; SILVEIRA, 2001) e, em certos casos, duopólios, ou mesmo, monopólios. A atual repartição e oligopolização do território nacional promovida pelas empresas aéreas, possibilita a elas extrair o máximo lucro possível das frações do território em que atuam, na medida em que permite às mesmas imporem aos lugares e usuários uma forte sujeição às suas políticas de mercado e estratégias de acumulação, incluindo-se aí o controle (às vezes, exclusivo) sobre a oferta de determinadas rotas aéreas, a definição dos horários de voos e a regulação dos preços de passagens.

Ademais, se o controle privilegiado sobre trechos da malha aérea nacional oferece às empresas condições vantajosas para a exploração econômica do território, por outro lado obriga também a definição de acordos entre empresas de diferentes portes para integração entre as linhas e trechos visando o intercâmbio de passageiros para o alcance de aeroportos sob controle de uma única companhia (CAMILO PEREIRA, 2014). Tais situações resultam em voos com uma maior quantidade de escalas e maior tempo de deslocamento para os passageiros, estabelecendo assim uma relativa oposição entre uma "fluidez potencial do território" (SANTOS; SILVEIRA, 2001) - possibilitada pela atual extensão da malha aérea nacional - e uma "fluidez 
efetiva" (Idem) - resultante das condições de acesso à malha aérea e (inter)conexão dos lugares estabelecidas pelas empresas.

As diferentes territorialidades das empresas aéreas (marcadas por extensões e configurações variadas) apontam assim para capacidades e estratégias distintas de uso do território (como mercado e como recurso), e revelam, igualmente, uma valorização desigual dos lugares promovida pelas mesmas. Adotando uma estratégia de uso econômico do território relativamente distinta daquela realizada por outras grandes companhias operantes no país, a Azul Linhas Aéreas constitui-se, por sua vez, num importante agente da expansão recente do sistema de transporte aéreo nacional devido, entre outras razões, a maior capilaridade territorial da malha aérea estabelecida pela empresa. Desta maneira, o estudo da topologia territorial da Azul se apresenta como um caso relevante para o entendimento da atual dinâmica de integração aérea do território brasileiro, bem como para a compreensão do uso seletivo, desigual e hierárquico do território promovido pelas empresas aéreas no país.

\section{INTEGRAÇÃO AÉREA E ESTRATÉGIAS DE USO CORPORATIVO DO TERRITÓRIO BRASILEIRO: O CASO DA AZUL LINHAS AÉREAS.}

Criada no ano de 2008, a Azul Linhas Aéreas iniciou suas atividades em um contexto da aviação comercial nacional marcado pela existência de um verdadeiro duopólio, visto que, naquele momento, Gol e Tam respondiam juntas por mais de $85 \%$ do mercado brasileiro de voos domésticos ${ }^{13}$.

Ao longo de uma década de existência, a atuação da Azul se caracterizou pela adoção de uma estratégia de uso do território relativamente distinta daquelas realizadas por outras grandes companhias aéreas atuantes no Brasil. Isso porque, por um lado, a empresa vem se destacando pela implantação de uma malha aérea mais difusa, que alcança um conjunto crescente de cidades regionais no interior do território brasileiro, não restringindo suas operações aos maiores aeroportos e principais eixos aeroviários do país. Por outro lado, a Azul também se notabilizou pela promoção da chamada "aviação de baixo custo" ("low-cost, low-fare"), oferecendo tarifas e passagens aéreas com preços menores, estratégia que contribuiu, até certo ponto, para um maior acesso da população com rendas mais baixas ao sistema de transporte aeroviário no Brasil.

Conforme destacam Valent, Dornelles e Valent (2014), os estudos prospectivos realizados pela empresa identificaram que apenas cerca de $5 \%$ da população brasileira utilizava o transporte aéreo com frequência, sendo este fato associado, entre outras razões, aos elevados preços das passagens aéreas no Brasil, em média 50\% superior (custo/km) àqueles cobrados nos Estados Unidos, por exemplo. De acordo com os autores, os estudos da companhia indicaram, também, que apesar da existência de um mercado nacional de aviação comercial duopolizado, algumas condições oferecidas pelo território brasileiro possibilitavam a atuação da Azul.

Dentre as condições identificadas pela companhia estavam: a) a existência de uma malha aérea nacional ainda limitada, concentrada junto às principais metrópoles brasileiras; b) a persistência de uma significativa infraestrutura de aeroportos de médio e pequeno porte subutilizada ou ociosa; c) a presença de novas demandas por rotas envolvendo cidades regionais ainda não atendidas pelas companhias aéreas operantes no país. Segundo Valent, Dornelles e Valent (2014, p. 138), diante deste

\footnotetext{
${ }^{13}$ Conforme a ANAC (2017), Webjet (4,4\%), Azul (3,7\%), Avianca (2,5\%), Trip (1,5\%) e outras pequenas empresas $(1,9 \%)$, respondiam juntas, por apenas 14,1\% do mercado de aviação comercial brasileira em 2009.
} 
quadro, um dos principais fatores que impulsionaram a criação da Azul e a constituição de sua malha aérea foi "a existência de uma demanda insatisfeita e a possibilidade de criar rotas alternativas de negócios em cidades pouco exploradas".

Sem contar inicialmente com a possibilidade de se inserir nos principais eixos aeroviários e ocupar os maiores aeroportos brasileiros - já amplamente explorados pelas grandes companhias aéreas instaladas no país (GOL e TAM) - a Azul definiu, então, o aeroporto de Viracopos, localizado no município de Campinas, estado de São Paulo, como seu "hub"14, isto é, seu principal centro de operações logísticas.

A escolha de Campinas pela Azul para sediar seu principal polo nacional de emissão e conexão de voos não foi aleatória. Ela ocorreu, entre outras razões, devido a ampla e subutilizada infraestrutura que o Aeroporto Internacional de Viracopos possuía para a realização de voos domésticos, bem como pelo próprio contexto territorial no qual Campinas se encontra inserida. Caracterizada como um grande pólo tecnológico e industrial, e como um dos mais importantes centros de negócios do país, Campinas se situa também próximo ao principal "centro de gestão do território brasileiro" - a metrópole de São Paulo ${ }^{15}$. Compondo, de certo modo, a "metrópole expandida"16, Campinas apresentava assim uma significativa demanda por sistemas de circulação rápidos e eficientes que permitissem a região se interligar, de maneira imediata, ao conjunto do território brasileiro.

Com os maiores aeroportos do país já operando próximo ao limite de suas capacidades e sendo utilizados por outras grandes companhias aéreas, o aeroporto de Viracopos e a região metropolitana de Campinas apresentavam, portanto, as condições (técnicas e territoriais) que possibilitavam a Azul realizar com eficácia suas estratégias de uso econômico do território brasileiro. Desse modo, atribuindo a Campinas o papel de principal centro de operações da companhia, a Azul iniciou, em dezembro de 2008, a implantação de sua malha aérea, a qual, desde então, se expandiu rapidamente, passando a alcançar um número crescente de regiões e cidades do país.

No seu primeiro ano de atividade, a Azul estabeleceu uma malha aérea relativamente restrita, ainda que de longo alcance, composta por apenas 14 destinos (ANAC, 2018a). Mesmo a empresa já demonstrando uma atuação territorial de escala nacional, neste primeiro instante a malha aérea da Azul privilegiava a interligação sobretudo de Campinas às capitais de alguns estados do país, especialmente àquelas das regiões Sul, Sudeste e Nordeste (Curitiba, Porto Alegre, Rio de Janeiro, Vitória, Belo Horizonte, Salvador, Maceió, Fortaleza, Recife), além de Manaus e Campo Grande nas regiões Norte e Centro-Oeste. Nesta fase, as únicas cidades que integravam a malha aérea da empresa que não se constituiam em capitais de estados eram Maringá e Navegantes, cidades que, por sua vez, desempenhavam importantes centralidades regionais nos seus respectivos estados (Paraná e Santa Catarina) (Figura 8).

Nos anos seguintes, a Azul ampliou sensivelmente o número de localidades incorporadas à sua malha aérea, passando a alcançar um total de 45 em 2011 (ANAC,

\footnotetext{
${ }^{14}$ Segundo a CNT (2015, p.11) o sistema Hub and Spoke "constitui-se a partir da determinação por parte das empresas aéreas de um aeroporto para ser o centro de suas operações de forma a otimizá-las. A adoção desse tipo de mecanismo de distribuições de voos reduz o número necessário de rotas para integrar os destinos, ao mesmo tempo em que expande a malha aérea".

${ }^{15}$ Campinas se situa a menos de $90 \mathrm{Km}$ de distância de São Paulo, e liga-se à metrópole paulistana de forma contigua, através de fartas infraestruturas de transporte rodoviário.

${ }^{16}$ Segundo Lencioni (2015), o continuum urbano que se estende do Rio de Janeiro, passa por São Paulo e alcança Campinas, se configura na "megarregião urbana" brasileira. De acordo com a autora, esse processo de urbanização dispersa revela um fenômeno de "urbanização regional". Segundo Hervé Terry (2003, p. 24), o aeroporto de Viracopos funcionaria, "[...] de fato, como o terceiro aeroporto da capital paulista".
} 
2018a). Além da manutenção dos destinos já estabelecidos, novas capitais de estados, especialmente nas regiões Nordeste, Centro-Oeste e Norte (São Luís, Teresina, Natal, Aracaju, Palmas, Goiânia, Cuiabá, Belém, Brasília, entre outras), passaram também a se constituir em lugares alcançados pela companhia. Além disso, concomitante a este movimento de incorporação de novas capitais estaduais à sua malha aérea, um conjunto maior de cidades passou a ser alcançado pela empresa, com destaque para algumas que se caracterizam como importantes centros regionais no interior do estado de São Paulo (Marília, Presidente Prudente, Ribeirão Preto, Araçatuba, São José do Rio Preto e São José dos Campos), além de cidades com semelhante papel na rede urbana de outros estados do país, como no Paraná (Maringá e Foz do Iguaçu), Santa Catarina (Joinvile), Minas Gerais (Uberaba), Ceará (Juazeiro do Norte) e Bahia (Ilhéus) (Figura 9).

Desse modo, com novas rotas aéreas estabelecidas a partir de Campinas e, posteriormente, Belo Horizonte, a Azul passou a dispor de uma malha aérea mais extensa, proporcionando uma maior integração aérea interna da região centro-sul, além de uma maior articulação desta macrorregião ao conjunto do território nacional.

\section{Azul - Malha Aérea (2009 e 2011)}
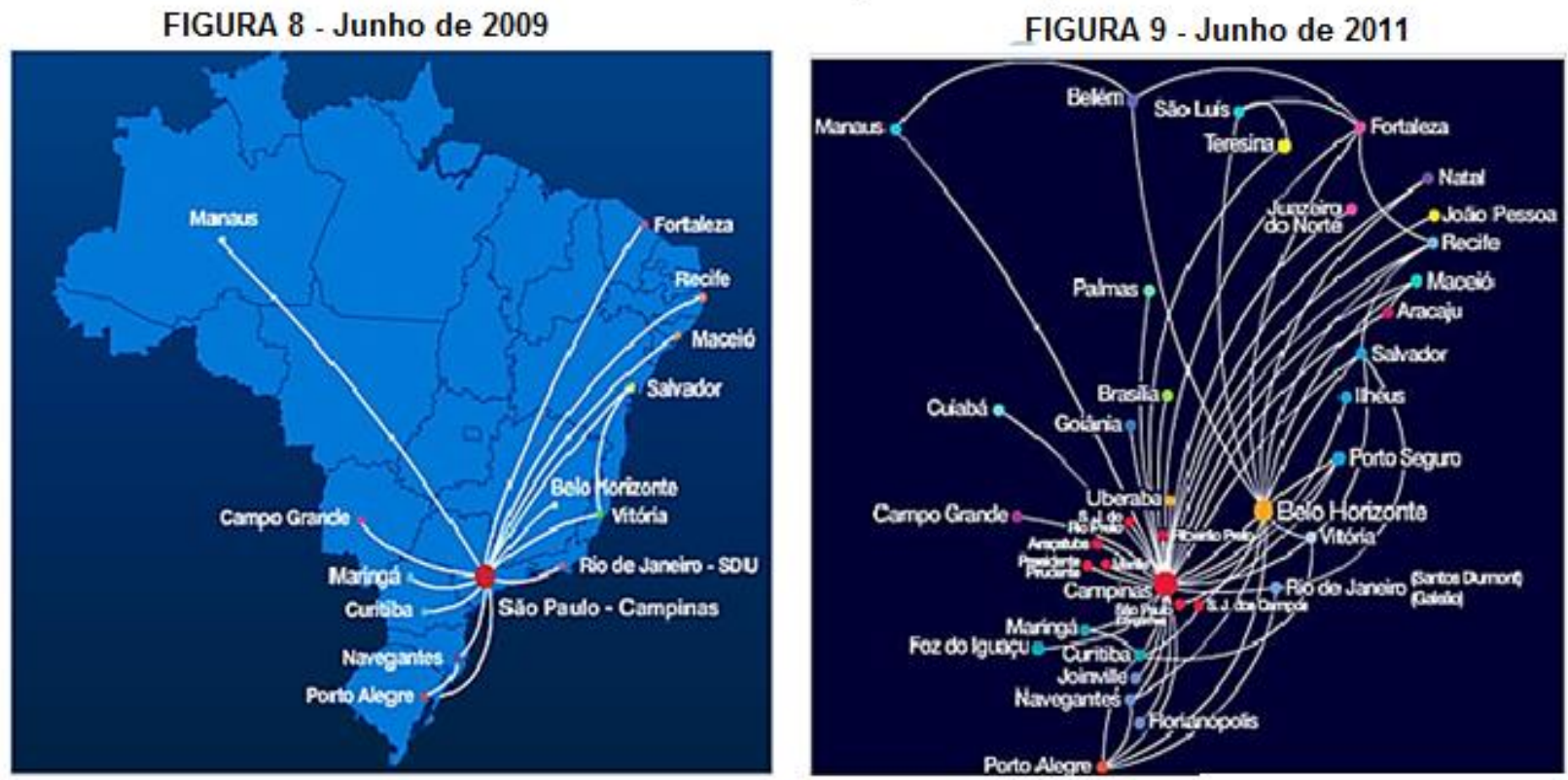

Fontes: ANAC, 2018b; Valente; Dorneles; Valent, 2014; Aviação Comercial.Net (2018).

A partir de 2012, a malha aérea da Azul passou por uma significativa expansão e assumiu uma configuração territorial marcadamente capilarizada. Com a fusão com a Trip Linhas Aéreas, a incorporação da malha aérea dessa empresa e a criação de novas rotas, o número de cidades alcançadas pela Azul no Brasil mais que dobrou, saltando de 45 destinos em 2011 para 105 em 2013, o que levou-a a se tornar a companhia de aviação regular com a maior malha aérea do país (ANAC, 2018a). Neste processo de ampliação do seu alcance territorial, uma clara estratégia de uso corporativo do território brasileiro passou também a ser promovida pela empresa: a exploração do mercado de aviação comercial regional.

Com a possibilidade aberta da empresa se inserir em novos aeroportos e operar novas rotas aéreas em diferentes regiões do Brasil (após a absorção da Trip) ${ }^{17}$,

\footnotetext{
${ }^{17}$ De acordo com dados do Anuário de Transporte Aéreo Brasileiro (ANAC, 2018a), a Trip Linhas aéreas foi responsável por transportar 6,4\% do total de 88.665.102 milhões de passageiros que utilizaram o sistema aéreo no país, em 2012. Ainda, no
} 
a companhia passou a alcançar um número expressivo de cidades no interior do país e, assim, constituiu uma malha aérea mais difusa e menos centralizada, caracterizada por estabelecer ligações diretas entre capitais de estados e centros regionais (Figuras 10 e 11). Excluindo-se as capitais de estados, que por sua própria centralidade política e econômica representam destinos prioritários para as grandes empresas aéreas, do total de 66 municípios que foram integrados a malha aérea da Azul entre 2012 e 2013, pelo menos 60 eram municípios que possuiam entre 7 mil e 500 mil habitantes, o que indica um nítido fenômeno de capilarização do malha aérea nacional comandada pela empresa no período (Gráfico 10).

Vale destacar que apesar de tal processo de expansão da malha aérea da Azul ter levado a consolidação de novos pólos responsáveis por centralizar e redistribuir os voos da empresa em escala regional (como foram os casos dos papéis exercidos por Salvador, Fortaleza, Manaus, Belém, Cuiabá e Brasília), esta situação não retirou a condição que desde o início foi atribuída sobretudo a Campinas, e em menor proporção a Belo Horizonte, de principais centros articuladores dos fluxos aéreos nacionais (voos inter-regionais e conexões) comandados pela empresa (Figura 11).

Malhas aéreas da Trip (2012) e da Azul (2013).
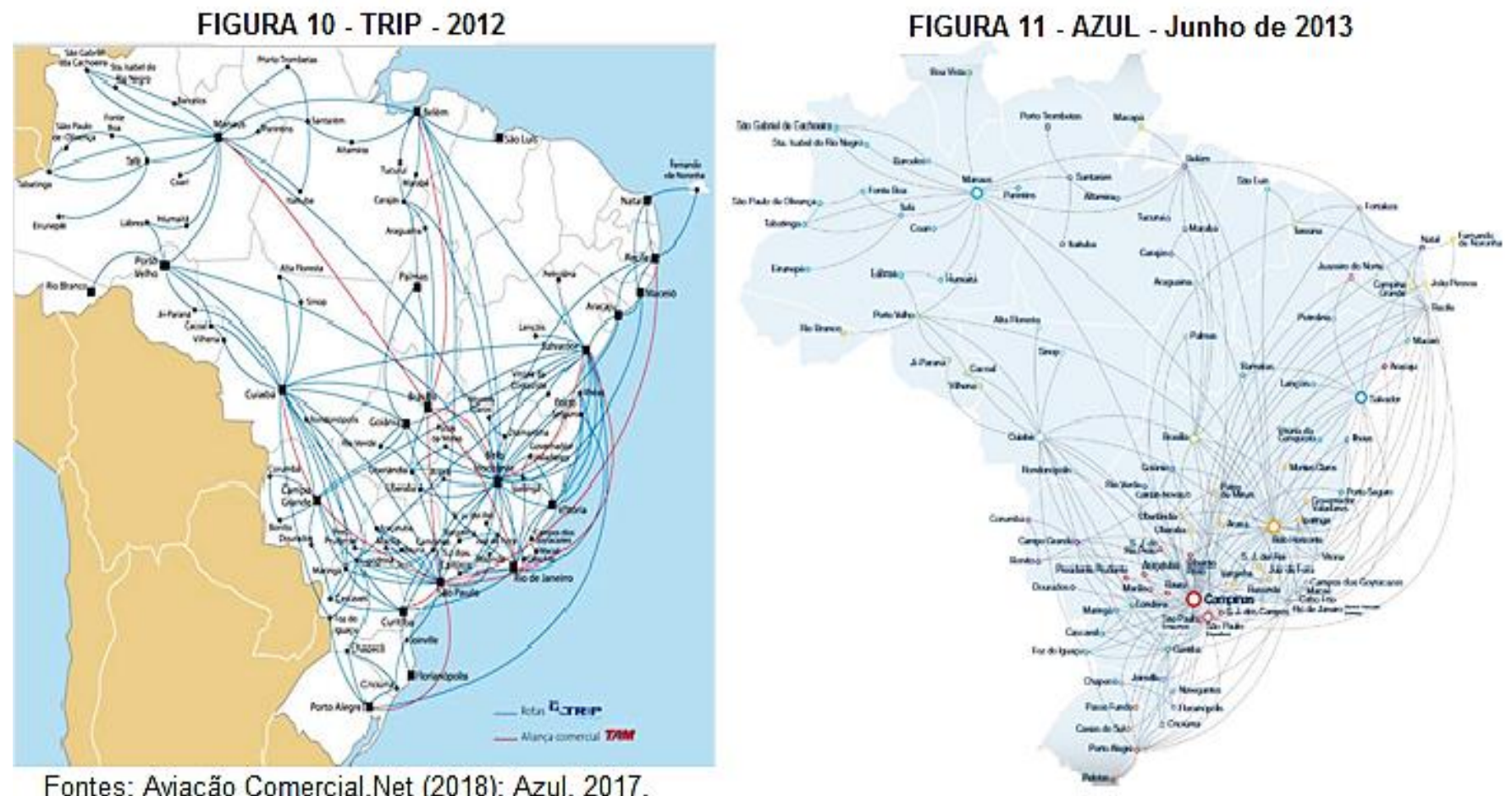

Fontes: Aviação Comercial.Net (2018); Azul, 2017.

Após seu vertiginoso processo de expansão, a atuação territorial da Azul manteve-se, relativamente, estável entre os anos de 2015 e 2017, com sua malha aérea oscilando de 106 a 100 municípios brasileiros alcançados durante o período (ANAC, 2018a). Tal situação consolidava a Azul como a empresa que utilizava o maior número de aeroportos no Brasil ${ }^{18}$, estendendo-se por quase a totalidade dos 
aeroportos que operavam voos regulares e não-regulares no país, os quais perfizeram o total de 124 no ano de 2017 (ANAC, 2018a) (Figuras 12 e 13). Entretanto, se, por um lado, a Azul se carcaterizava na companhia que utilizava o maior número de aeroportos e operava o maior número de voos no país (31\% do total dos voos domésticos realizados no ano de 2017) ${ }^{19}$, Gol e Latam, mesmo utilizando um número bem menor de aeroportos (57 e 47, respectivamente), foram responsáveis por transportar um número maior de passageiros $(33,6 \%$ e $31,0 \%$ do total, respectivamente), resultado da atuação destas companhias ser territorialmente mais seletiva, se concentrando, sobretudo, nos aeroportos e eixos aeroviários mais movimentados do país ${ }^{20}$ (Gráficos 2 e 3).

\section{Azul - Malha Aérea (2015 e 2017)}


Fontes: Azul, 2017; Aviação Comercial.Net (2018).

Vale destacar que a estratégia de uso econômico do território estabelecida pela Azul - baseada na constituição de uma malha aérea mais capilarizada e na exploração de rotas entre capitais de estados e centros regionais - permitiu a empresa realizar um uso privilegiado, às vezes mesmo monopolista, de determinados aeroportos e ligações aéreas no país. Em 2017, era possível contabilizar 40 municípios brasileiros em que a Azul operava em regime de monopólio; municípios cujas populações

\footnotetext{
${ }^{19}$ Do total de 805.448 voos domésticos realizados no Brasil em 2017, a Azul foi responsável por 31\%, Gol, 29\%, Latam, 25\%, Avianca, 11\%, enquanto as demais companhias aéreas representaram, juntas, 4\% (ANAC, 2018a).

${ }^{20}$ Cumpre destacar que considerando as infraestruturas aeroportuárias e as estratégias de transporte utilizadas, a discrepância entre o número de passageiros transportados e o número de voos realizados por cada companhia pode ser assim explicada: enquanto GOL e LATAM operam nos maiores aeroportos brasileiros (dotados de grande infraestrutura aeroportuária) e conseguem empregar aeronaves de grande porte (Boengs e Airbus, que transportam de 140 a 220 passageiros), atendendo assim a significativa demanda por transporte aéreo presente nos grandes centros urbanos em que predominantemente atuam, a Azul, por sua vez, opera em aeroportos com infraestruturas aeroportuárias mais limitadas (com pistas menores, por exemplo), e cidades e regiões com uma demanda menor de passageiros, fazendo assim do emprego de aeronaves de menor porte (como Jatos Embraer e aviões tuboélices, com capacidades de transporte de passageiros que variam entre 50 e 120) uma necessidade para a realização de suas operações.
} 
variavam de 10 mil a 560 mil habitantes e que se constituiam em relevantes pólos regionais (Tabela 4). Após a incorporação da Trip, a intensificação do processo de concentração de capitais no setor, e a criação de novas rotas aéreas pela empresa, a Azul passou a deter o controle exclusivo da operação de voos em muitos aeroportos e rotas entre cidades de pequeno e médio portes, o que possibilitou a empresa explorar esse mercado sem sofrer concorrência direta de outras companhias.

TABELA 4 - Municípios com atuação exclusiva da Azul Linhas Aéreas - 2017.

\begin{tabular}{|c|l|c|l|}
\hline ESTADOS & MUNICÍPIOS & ESTADOS & MUNICíPIOS \\
\hline AMAZONAS & Tabatinga & PARÁ & Carajás \\
\hline BAHIA & $\begin{array}{l}\text { Feira de Santana, Lençois, Paulo Afonso, } \\
\text { Teixeira de Freitas e Valença }\end{array}$ & PIAUÍ & Paranaíba \\
\hline GOIÁS & Rio Verde & $\begin{array}{c}\text { RIO DE } \\
\text { JANEIRO }\end{array}$ & Campos dos Goytacazes e Cabo Frio \\
\hline $\begin{array}{c}\text { MINAS } \\
\text { GERAIS }\end{array}$ & $\begin{array}{l}\text { Juiz de Fora, Uberaba, Ipatinga, } \\
\text { Governador Valadares, Varginha, } \\
\text { Divinópolis, Araxá e Montes Claros }\end{array}$ & $\begin{array}{c}\text { RIO } \\
\text { GRANDE } \\
\text { DO SUL }\end{array}$ & $\begin{array}{l}\text { Uruguaiana, Santo Angelo, Santa } \\
\text { Maria, Pelotas e Passo Fundo }\end{array}$ \\
\hline $\begin{array}{c}\text { MATO } \\
\text { GROSSO }\end{array}$ & Sorriso, Sinop e Alta Floresta & RONDÔNIA & Vilhena, Ji-Paraná e Cacoal \\
\hline $\begin{array}{c}\text { MATO } \\
\text { GROSSO SUL }\end{array}$ & $\begin{array}{l}\text { Dourados, Barra dos Garças, Bonito e } \\
\text { Corumbá }\end{array}$ & $\begin{array}{c}\text { SANTA } \\
\text { CATARINA }\end{array}$ & Lages \\
\hline $\begin{array}{c}\text { PARANÁ } \\
\text { Ponta Grossa e Cascável }\end{array}$ & $\begin{array}{c}\text { SÃO } \\
\text { PAULO }\end{array}$ & Marília, Bauru e Araçatuba \\
\hline
\end{tabular}

Fonte: ANAC, 2018c.

Além desta marcante atuação da Azul no mercado de aviação regional, a inserção da empresa em alguns aeroportos de grandes cidades brasileiras propiciou também a companhia obter um controle crescente sobre importantes trechos da malha aérea nacional. A partir da indentificação de demandas por rotas aéreas não atendidas, e adotando estratégias agressivas de apropriação do mercado (tarifas "lowcost, low-fare"), a empresa criou e/ou ampliou rotas e passou a viabilizar a articulação aérea em escala regional e nacional de importantes centros urbanos do país. Em 2017, a maioria dos voos regulares que partiam dos aeroportos de Campinas, Belo Horizonte, Curitiba, Porto Alegre, Recife, Cuiabá e Goiânia, por exemplo, já eram comandados pela Azul (Gráfico 2).

Desse modo, com a consolidação de suas estratégias corporativas de uso do território, a Azul, num intervalo relativamente curto de tempo, se consolidou como a terceira maior companhia aérea do país, passando a responder, em 2017, por 22,8\% do mercado brasileiro de voos domésticos. Contudo, se, por um lado, a política de integração aérea comandada pela Azul permitiu a mesma beneficiar-se das possibilidades de acumulação oferecidas pelo território brasileiro ${ }^{21}$, por outro lado, as estratégias implantadas pela companhia não foram suficientes para romper com as barreiras (econômicas e territoriais) que limitam um acesso mais amplo da população ao sistema de transporte aéroviário, muito menos conseguiu assegurar uma integração plena do território nacional.

Deve-se ressaltar que em cidades menores, onde a oferta de voos é reduzida e companhias operam em regime de monopólio, as passagens aéreas costumam apresentar preços relativamente elevados (custo por kilometro), dificultando o acesso a este tipo de transporte para uma grande parcela da população local/regional. Em

\footnotetext{
${ }^{21} \mathrm{Se}$, ao longo dos primeiros anos de atividade a empresa acumulou déficits em suas operações, nos últimos anos a atuação territorial da Azul propiciou a ela obter ganhos econômicos. Em 2017 e 2018, os lucros da empresa atingiram R $\$ 529$ e R $\$ 703,6$ milhões, respectivamente (MELO; BOUÇAS, 2019), indicando o relativo sucesso obtido pela empresa com a efetivação de sua política corporativa de articulação aérea do território.
} 
estudo específico, o IBGE (2013) já havia destacado que os habitantes dos grandes centros urbanos se caracterizam, de modo geral, naqueles indivíduos que potencialmente são dotados de maior mobilidade aeroviária. Isso porque, a maior frequência de voos nestes centros se constitui numa vantagem, assim como o preço relativamente mais baixos das passagens (custo por kilometro) - relacionada a alguma concorrência estabelecida entre as companhias aéreas - favoreciam o acesso da população local/regional ao sistema de circulação aéreo.

Deve-se ainda salientar que, além de ser restrito o número de municípios brasileiros dotados de aeroportos ${ }^{22}$, sob a lógica do mercado apenas os lugares economicamente rentáveis são, de fato, objeto de interesse e incorporados à malha aérea das empresas, enquanto os demais lugares são colocados à margem, ou mesmo excluídos do processo de integração aérea do território. No caso da Azul, pôde-se observar, ao longo do desenvolvimento de suas estratégias econômicas de uso do território, que enquanto uma gama de lugares foi progressivamente incorporada à sua malha aérea regular, um outro conjunto de lugares, após terem sido integrados, foram, posteriormente, preteridos pela empresa, isto é, desconectados de sua malha aérea entre os anos de 2013 e 2017. Estes, por exemplo, foram os casos de Rio Branco no estado do Acre; Barcelos, Fonte Boa, Humaitá, São Paulo de Olivença, Santa Isabel do Rio Negro, Eirunepé e Coari no estado do Amazonas; Tucuruí, Itaituba e Porto Trombetas no Pará; Araguaína em Tocantins; Parnaíba no Piauí; Pato de Minas, Juiz de Fora e São João del Rei em Minas Gerais; Macaé e Resende no Rio de Janeiro; Araraquara e São José dos Campos em São Paulo, e Criciúma em Santa Catarina.

Assim, apesar de ser possível observar um verdadeiro processo de expansão e capilarização dos fluxos aéreos nacionais nos últimos anos, pode-se também dizer que a atual dinâmica de integração aérea do território brasileiro tende a ocorrer de maneira seletiva, privilegiando especialmente aqueles lugares e regiões capazes de proporcionar maiores ganhos econômicos para as empresas. Não obstante, dessa maneira vemos também uma nova geografia das desigualdades sendo (re)criada no território brasileiro, na medida em que sob o comando das empresas, e sob a lógica mercantil de valorização dos lugares, determinadas frações do território são incorporadas às redes de circulação rápida do território nacional, enquanto as demais são deixadas à margem desse processo de integração territorial.

\section{CONSIDERAÇÕES FINAIS}

Como vimos, o atual processo de integração aérea nacional vem possibilitando a incoporação de novas parcelas do território às modernas redes de circulação, proporcionando uma maior articulação entre os lugares e regiões do país. Todavia, para a ocorrência de tal expansão do sistema de transporte aéreo nacional contribuiu, por um lado, as demandas por circulação rápida estabelecidas pela nova divisão territorial do trabalho, ao passo que, por outro lado, a "desregulação do setor aéreo" brasileiro favoreceu a ampliação das ações e do poder de comando das empresas aéreas sobre a (re)configuração da malha aérea nacional.

Tal situação de expansão e regulação corporativa do sistema de transporte aéreo brasileiro constitui uma realidade relativamente distinta daquela vigente em momento anterior. Enquanto durante as décadas de 1970 e 80 o Estado, de maneira

\footnotetext{
${ }^{22}$ Dos mais de 5.500 municípios existentes no Brasil, apenas 135 eram servidos por aeroportos e 124 aeroportos operaram voos regulares e não regulares em 2017 (IBGE, 2013; ANAC, 2018a).
} 
centralizada, era responsável por definir rotas aéreas, controlar tarifas e delimitar os espaços de atuação de cada companhia aérea no território brasileiro (MALAGUTTI, 2001); a partir dos anos 1990, com a "desregulação" do mercado brasileiro de voos domésticos, aqueles atributos passaram a ser cada vez mais competência das empresas, às quais, conforme seu poder político e econômico, e de acordo com as possibilidades de ação oferecidas pelos lugares, puderam, através de suas estratégias particulares de uso do território redefinir sua territorialidade e suas escalas territoriais de atuação.

Daí, não ser exagero dizermos que passamos de um período em que a política de integração aérea do território era comandado pelo Estado, para um período em que a política de integração aérea do território passou a ser comandada pelas empresas, sendo submetida, portanto, à lógica do mercado e às estratégias particularistas de uso econômico do território estabelecidas pelas companhias.

Conforme foi possível avaliar ao longo do trabalho, a atual dinâmica de integração aérea do território passou a estar sujeita à racionalidade do mercado, e os pontos do território incorporados à rede aérea nacional são, consequentemente, aqueles economicamente mais rentáveis para as operações das companhias. Assim, realiza-se, essencialmente, um processo de (des)valorização mercantil dos lugares, ao passo que o processo de integração do território nacional se revela como sendo crescentemente seletivo, desigual e hierárquico, apesar da ampliação dos fluxos aéreos vista recentemente. Sob outro ponto de vista, pode-se dizer que se opera também uma segmentação do território enquanto mercado, na medida em que as companhias aéreas mais proeminentes se apropriam dos aeroportos e dos eixos aéreos mais movimentados e, portanto, mais lucrativos do país, deixando o restante do território para as empresas aéreas de menor porte.

Neste sentido, a Azul Linhas aéreas se apresentou como um caso ímpar no Brasil. Isso porque a empresa desempenhou papel fundamental no processo de expansão do sistema aéreo nacional. Diferentemente das outras grandes companhias aéreas atuantes no país, a Azul opera destacadamente na interligação de centros regionais, revelando um nítido movimento de capilarização territorial dos fluxos aéreos nacionais. Sem inicialmente dispor das possibilidades e da força para se inserir nos aeoroportos e nos eixos aeroviários mais movimentados do país, já amplamente apropriados por outras grandes empresas aéreas, a Azul assumiu assim uma territorialidade particular, mais difusa e capilarizada, e se destacou por desenvolver novas estratégias de uso econômico do território.

Não é demais salientar que tal estratégia territorial da Azul não é fortuita, mas sim esteve ajustada às novas demandas por circulação rápida instituída no Brasil com o processo de reorganização produtiva do território, fenômeno que atribuiu às cidades regionais funções produtivas crescentes na moderna divisão territorial do trabalho. Neste sentido, com a expansão do sistema aéreo nacional, observa-se também o reforço de novos padrões de interações espaciais, nos quais os centros urbanos brasileiros - cidades regionais e centros nacionais de gestão do território - se articulam, cada vez mais de maneira direta (SANTOS, 1994). A produção desta maior fluidez do território constitui-se numa condição para que os modernos circuitos espaciais de produção e círculos de cooperação (SANTOS; SILVEIRA, 2001) que perpassam o território brasileiro - estabelecendo articulações territoriais em escala nacional e mesmo internacional - possam operar.

Contudo, como foi também observado no decorrer deste trabalho, o processo de expansão do sistema aéreo nacional, ao ser comandado pelas empresas e estar sujeito aos propósitos do mercado, não promove uma integração plena do território. 
Isso porque, tal processo de integração aérea nacional se revela como sendo essencialmente seletivo, privilegiando alguns lugares e desprezando outros. Assim, na medida em que alguns lugares e frações valorizadas do território são incorporados às redes de circulação aérea, tornando-se autênticos "espaços da rapidez", outros lugares convertem-se em verdadeiros "espaços da lentidão"23 (SANTOS; SILVEIRA, 2001), isto é, espaços onde tais redes estão ausentes ou operam de forma irregular. Desse modo, observa-se também a (re)criação das desigualdades no Brasil no período atual, algo que pode ser visto através da maior ou menor aptidão que determinadas frações do território possuem para viabilizar a circulação rápida de pessoas, mercadorias e informações.

Por fim, diante do que foi exposto, pode-se então dizer que se a atual política de integração aérea nacional leva apenas a uma integração parcial e seletiva do território, produzindo como uma de suas consequencias o aprofundamento de desigualdades entre os lugares, é porque a razão última que preside tal processo não é a promoção da integração plena do território, mas sim a busca pela acumulação corporativa, algo que para ser alcançado depende, todavia, das oportunidades econômicas ímpares que cada fração do território oferece para as empresas.

\section{BIBLIOGRAFIA}

ANAC - Agência Nacional de Aviação Civil. Anuários do Transporte Aéreo (Vários números). Brasília, 2018a. Disponível em: http://www.anac.gov.br/assuntos/dados-eestatisticas/mercado-do-transporte-aereo. Diversos acessos entre 7/2017 e 8/2018.

. Consulta Interativa - Indicadores do Mercado de Transporte Aéreo (Banco de dados). 2018b. Disponível em: http://www.anac.gov.br/assuntos/dados-eestatisticas/mercado-de-transporte-aereo/consulta-interativa/demanda-e-ofertaorigem-destino. Diverssos acessos entre 7/2017 e 8/2018.

Consulta de Voos Passados - VRA. (Banco de dados). 2018c. Disponível em: https://sas.anac.gov.br/sas/siros/. Diverssos acessos entre 6/2017 e 8/2018.

. Consulta Interativa - Painel dos Indicadores do Transporte Aéreo. 2017. Disponível em: https://www.anac.gov.br/assuntos/dados-e-estatisticas/mercado-detransporte-aereo/painel-de-indicadores-do-transporte-aereo. Acessos em 8/2018.

ASTA LINHAS AEREAS. Rotas. Disponível em: http://www.voeasta.com.br/asta.html. Diversos acessos entre Fevereiro e Abril de 2018.

AZUL LINHAS AÉREAS. Azul Magazine. Ferrari; São Paulo. (Várias Edições). 2017. AVIAÇÃO COMERCIAL.NET. Mapa de Rotas. Disponível em: https://www.aviacaocomercial.net/mapaderotas.htm. Diverssos acessos entre 7/2017 e 8/2018.

AVIANCA LINHAS AÉREAS. Avianca em Revista. Media On Board; São Paulo, 6/2016.

BIELSCHOWSKY; CUSTODIO. A evolução do setor de transporte aéreo brasileiro. Revista Eletrônica Novo Enfoque, 2011, v. 13 n. 13 p. 72-93.

CAMILO PEREIRA, A. P. Asas da centralidade em céus conhecidos: a dinâmica territorial do setor de transporte aéreo no território brasileiro. Tese (Doutorado

\footnotetext{
${ }^{23}$ Santos e Silveira (2001) consideram que "os espaços da rapidez são, do ponto de vista material, os dotados de maior número de vias (e vias de boa qualidade), de mais veículos privados (e de veículos mais modernos e velozes), de mais transportes públicos com horários mais freqüentes, convenientes e precisos e também mais baratos). Do ponto de vista social, os espaços da rapidez serão aqueles onde é maior a vida de relações, fruto da atividade econômica ou sociocultural, ou então zonas de passagem, respondendo a necessidades de uma circulação mais longínqua. Os espaços da rapidez e os da lentidão se distinguem também em função da importância da divisão do trabalho, sobretudo quando ela é interna à região, e também da variedade e da densidade dos consumos".
} 
em Geografia). Universidade de São Paulo/Faculdade de Filosofia, Letras e Ciências Humanas. São Paulo, 2014.

CASTILLO, R.; FREDERICO, S. Espaço geográfico, produção e movimento: uma reflexão sobre o conceito de circuito espacial produtivo. Sociedade \& Natureza, Uberlândia, 22 (3); 461-474, dez. 2010.

CNT - Condederação Nacional de Transporte. Transporte e economia - Transporte aéreo de passageiros. Brasília: CNT, 2015.

CORDEIRO, H. K.; LADEIRA, F.S. O espaço aéreo favorece a desterritorialidade? In: SANTOS, M.; SOUZA, M. A,; SILVEIRA, M. L. Território: globalização e fragmentação. São Paulo: Hucitec/ Anpur, 1994.

CORREA, R. LOBATO. Os centros de gestão do território: uma nota. Revista Território, 1 (1), 1996, p. 23-30.

Corporação, práticas espaciais e gestão do território. Anuário IGEO/UFRJ Departamento de Geografia, V.15, Rio de Janeiro, p. 35- 41, 1992.

GALLO, F. O papel do transporte aéreo na integração do território brasileiro. (Dissertação de Mestrado). Unicamp/Instituto de Geogiência. Campinas, 2006.

A importância do sistema de movimento aéreo flexível na integração produtiva do território brasileiro: o papel dos contatos face a face na economia globalizada. Anais do X EGAL - De 20 à 26/3/2005 - Universidade de São Paulo p. 5660-5671. IBGE - Instituto Brasileiro de Geografia e Estatística. Redes e Fluxos do Território Ligações Aéreas 2010. Rio de Janeiro, 2013.

LATAM LINHAS AÉREAS. Revista Vamos. New Content; São Paulo, 6/2020.

LENCIONI, S. Urbanização difusa e a constituição de megarregiões: o caso de São Paulo - Rio de Janeiro. E-metropolis. Rio de Janeiro, Vol. 6, № 22, 2015, p. 6-15.

MALLAGUTTI. Evolução da Aviação Civil no Brasil. Consultaria Legislativa da Camara dos Deputados. Brasilia, Agosto de 2001.

MAP LINHAS AÉREAS. Nossos Destinos. Disponível em: https://voemap.com.br/destinos/. Diversos acessos entre Fevereiro e Abril de 2018.

MELO, A.; BOUÇAS, C. Lucro da Azul aumenta 36\% e atinge mais de $\mathrm{R} \$ 703$ milhões em 2018. In: Valor Econômico. (Publicado em: 14/03/2019). Disponível em: https://valor.globo.com/empresas/noticia/2019/03/14/lucro-da-azul-aumenta-36-eatinge-mais-de-r-703-milhoes-em-2018.ghtml.

OLIVEIRA, L. F. A. Análise da concentração no mercado doméstico de aviação civil entre 2001 e 2012. (Trabalho de Conclusão de Curso). Graduação em Ciências Econômicas, UFRGS. Porto Alegre, 2012.

PASSAREDO LINHAS AÉREAS. Destinos. Disponível em: https://voepassaredo.com.br/empresa/site/malha-geral. Diversos acessos entre Fevereiro e Abril de 2018.

SANTOS, M. A urbanização brasileira. São Paulo: Hucitec, 1994.

SANTOS, M. et al. O papel ativo da geografia: um manifesto. Revista Território, Rio de Janeiro, ano V, n.9, p.103-109, jul./dez. 2000.

SANTOS, M. e SILVEIRA, M. L. O Brasil: Território e Sociedade no início do século XXI. 2 ed. Rio de Janeiro: Record, 2001.

SAC - SECRETARIA DA AVIAÇÃO CIVIL. O Brasil que Voa. 2015. Disponível em: http://transportes.gov.br/obrasilquevoa/perfil-do-passageiro.php. Acessos: Jun/2017. SILVEIRA, M. L. Argentina: Território e Globalização. São Paulo; Brasiliense, 2003. TERRY, H. O transporte aéreo no Brasil: asas da centralidade. Mercator - Revista de Geografia da UFC. Fortaleza, Ano 2, № 3, 2003, pp.19-25. 
VALENT, V.; DORNELLES, G; VALENT, J. A inserção da Azul Linhas Aéreas no mercado brasileiro: o estudo descritivo de uma estratégia inovadora. Revista de Administração e Inovação, São Paulo, v. 11, n.3, p.125-149, jul./set. 2014. 